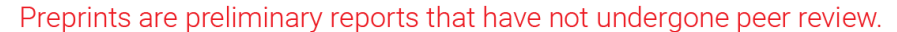 They should not be considered conclusive, used to inform clinical practice, or referenced by the media as validated information. \\ Bifunctional biomorphic SiC ceramics embedded molten salts for ultrafast thermal and solar energy storage
}

\section{Xu Qiao}

Nanjing University of Aeronautics and Astronautics

Xianglei Liu ( $\nabla$ xliu@nuaa.edu.cn )

Nanjing University of Aeronautics and Astronautics

Qinyang Luo

Nanjing University of Aeronautics and Astronautics

Yanan Song

Nanjing University of Aeronautics and Astronautics

\section{Haolei Wang}

Nanjing University of Aeronautics and Astronautics

\section{Meng Chen}

Nanjing University of Aeronautics and Astronautics

\section{Yimin Xuan}

Nanjing University of Aeronautics and Astronautics

\section{Yongliang $\mathrm{Li}$}

School of Chemical Engineering, University of Birmingham

\section{Yulong Ding}

School of Chemical Engineering, University of Birmingham

\section{Article}

Keywords: Thermal energy storage, solar energy, biomorphic silicon carbide, ceramics, thermal conductivity

Posted Date: January 18th, 2021

DOI: https://doi.org/10.21203/rs.3.rs-142337/v1

License: (c) (1) This work is licensed under a Creative Commons Attribution 4.0 International License. Read Full License 
Submitted to Nature Communications on 2021/01/06

\title{
Bifunctional biomorphic SiC ceramics embedded molten salts for ultrafast thermal and solar energy storage
}

\author{
Qiao Xu ${ }^{1}$, Xianglei Liu ${ }^{1 *}$, Qingyang Luo ${ }^{1}$, Yanan Song ${ }^{1}$, Haolei Wang ${ }^{1}$, Meng \\ Chen $^{1}$, Yimin Xuan ${ }^{1}$, Yongliang $\mathrm{Li}^{2}$, Yulong Ding ${ }^{2}$ \\ 1 School of Energy and Power Engineering, Nanjing University of Aeronautics \\ and Astronautics, Nanjing 210016, China \\ 2 Birmingham Centre for Energy Storage, School of Chemical Engineering, \\ University of Birmingham, Birmingham B15 2TT, UK \\ *Corresponding author e-mail: xliu@nuaa.edu.cn
}

\begin{abstract}
Phase change materials (PCMs) are regarded as one of the most promising candidates for thermal energy storage due to possessing large energy storage densities and maintaining nearly a constant temperature during charging/discharging processes. However, the intrinsically low thermal conductivity of PCMs has become a bottleneck for rapid energy transport and storage. Here, we present a strategy to achieve ultrafast solar and thermal energy storage based on biomorphic $\mathrm{SiC}$ skeletons embedded $\mathrm{NaCl}-$ $\mathrm{KCl}$ molten salts. A record-high thermal conductivity of $116 \mathrm{~W} / \mathrm{mK}$ is achieved by replicating cellular structure of oak wood, leading to an ultrafast thermal energy storage rate compared with molten salts alone. By further decorating TiN nanoparticles on $\mathrm{SiC}$ skeletons, the solar absorptance is enhanced to be as high as $95.63 \%$ via exciting broadband plasmonic resonances. Excellent thermal transport and solar absorption properties enable designed composites to have bifunctional capabilities of harvesting both thermal energy and solar energy very rapidly. This work opens a new route for the design of bifunctional energy storage materials for ultrafast solar and thermal energy storage.
\end{abstract}

Keywords: Thermal energy storage; solar energy; biomorphic silicon carbide; ceramics; thermal conductivity 


\section{Introduction}

Thermal energy storage can bridge the gap between thermal energy supply and consumption, thus playing a vital role in improving overall efficiency and reliability of thermal energy harvesting and utilization systems ${ }^{1-4}$. Among various thermal energy storage materials, phase change materials (PCMs) have been regarded as promising candidates since large amount of heat can be stored or released during phase change processes $^{5-15}$. Besides large energy storage densities, nearly a constant temperature is maintained during thermal energy charging/discharging processes, making output thermal energy have very small temperature variations. However, the intrinsically low thermal conductivity of PCMs $(<1 \mathrm{~W} / \mathrm{mK})$ makes thermal energy storage process slow ${ }^{8}$, which leads to low thermal energy storage efficiency and low power density. Past efforts in addressing this problem were mainly focused on adding high thermal conductivity fillers into PCMs, such as graphite ${ }^{16-20}$, graphene ${ }^{21}$, metal or metal oxide particles $^{22-24}$, metal foams ${ }^{25-31}$, carbon nanotubes ${ }^{32}$, and carbon skeleton ${ }^{33-37}$. Although effective to some extent ${ }^{20,32,38-40}$, the improvement of thermal conductivity remains limited, so that there is still a long way to realized fast thermal energy transport and storage. techniques can avoid above redundant energy transfer processes, and are more promising for efficient solar energy harvesting. However, most PCMs have poor solar absorption properties, leading to a low solar energy harvesting efficiency. Besides, the low thermal conductivity of PCMs again inhibits fast solar energy harvesting and may 
as carbon nanotubes ${ }^{32,41-44}$, graphite $e^{45-48}$, and graphene ${ }^{49-52}$, have been demonstrated to improve both solar absorptance and thermal conductivity of PCMs. Nevertheless, these materials suffer from oxidation problems especially at high temperatures. Therefore, achieving efficient and fast solar energy storage remains a formidable challenge.

Here, we present a strategy to achieve ultrafast thermal and solar energy storage based on biomorphic SiC skeletons embedded NaCl-KCl molten salts, as shown in Fig. 1b. SiC ceramic is chosen due to its high thermal conductivity, good thermal shock resistance, and inertness to oxygen or molten salts. Referring to wood's excellent performance in transporting water and mass, wood-like biomorphic porous $\mathrm{SiC}$ skeletons are fabricated, and the thermal conductivity of PCMs is tremendously enhanced from $0.84 \mathrm{~W} / \mathrm{mK}$ to $116 \mathrm{~W} / \mathrm{mK}$. Solar absorption can also be enhanced from $22.45 \%$ to $82.00 \%$. By further decorating TiN nanoparticles (NPs) on porous $\mathrm{SiC}$ skeletons, the solar absorptance is further enhanced to be as high as $95.63 \%$ via exciting broadband plasmonic resonances. Excellent thermal transport and solar absorption properties enable designed composites to have bifunctional capabilities of harvesting both thermal energy and solar energy very rapidly.
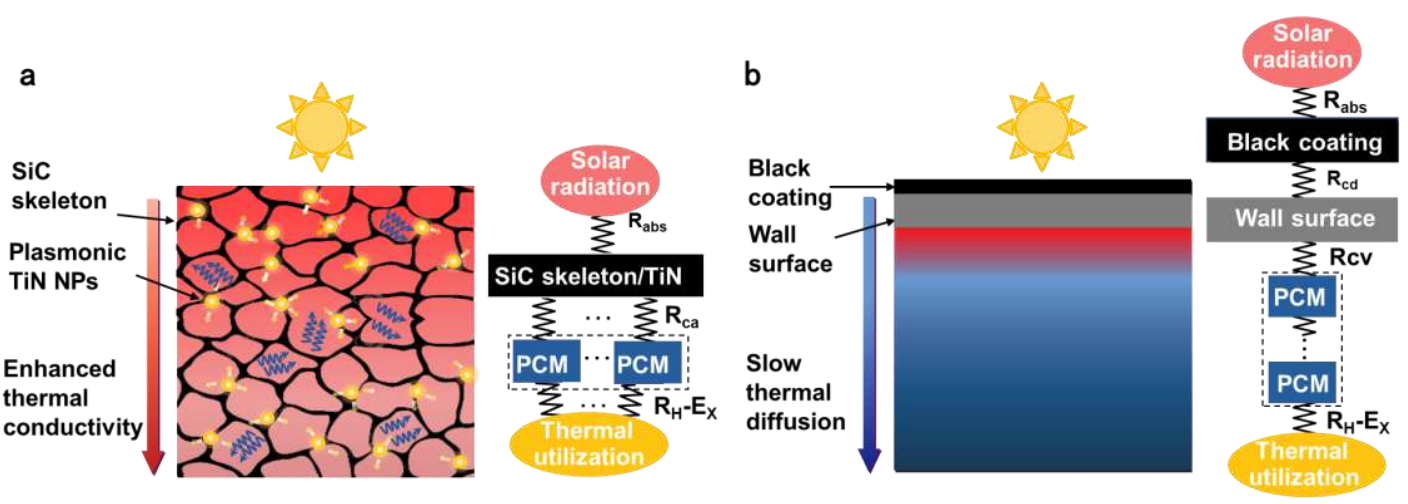

Figure 1. Schematic illustration of solar energy storage. a Integrated solar thermal conversion and energy storage. b Conventional surface-type.

\section{Results}

Ultrahigh thermal conductivity enabled by biomorphic $\mathrm{SiC}$ foams. Biomorphic $\mathrm{SiC}$ foams used in this study are fabricated by reactive infiltration of molten silicon into 
carbonized wood ${ }^{53-57}$. Briefly, the wood is first dried for 2 3 days (Fig. 2a), followed

81 by pyrolyzation and cutting, (Fig. 2b), molten silicon infiltration (Fig. 2c), and then

82 silicon removement (Fig. 2d). After that, TiN or $\mathrm{MnFe}_{2} \mathrm{O}_{4}$ NPs are decorated on

83 biomorphic SiC skeleton surface via dip coating methods, as shown in Fig. 2e. Finally,

84 eutectic salts are infiltrated into porous $\mathrm{SiC}$ skeleton to make biomorphic $\mathrm{SiC} / \mathrm{TiN}$ -

85 NaCl-KCl composites (Fig. 2f).
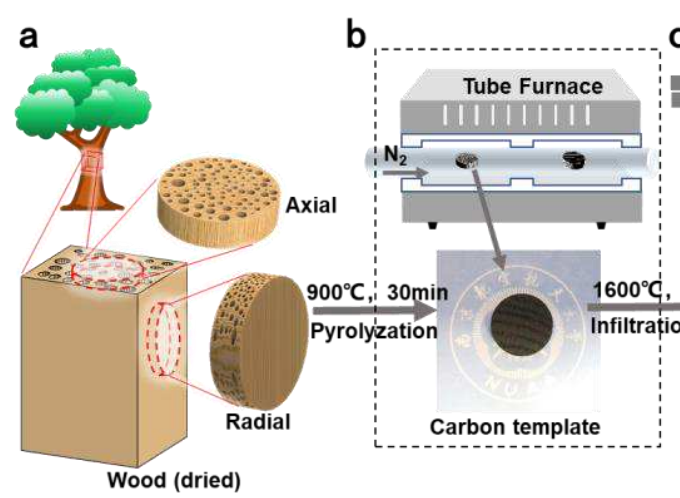

Carbon template

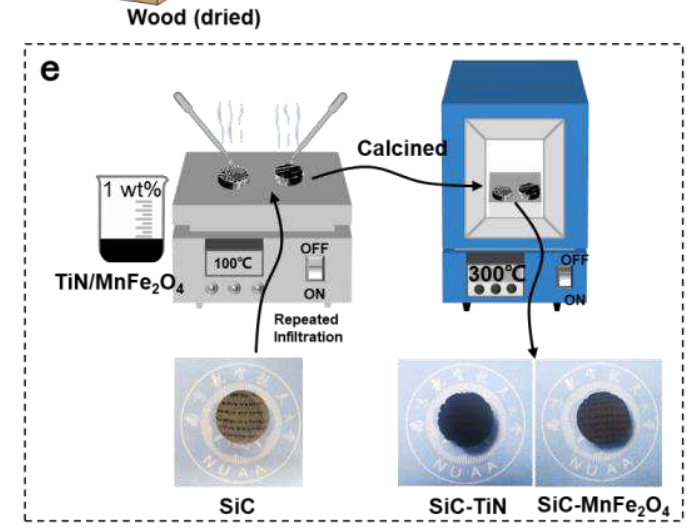

c d

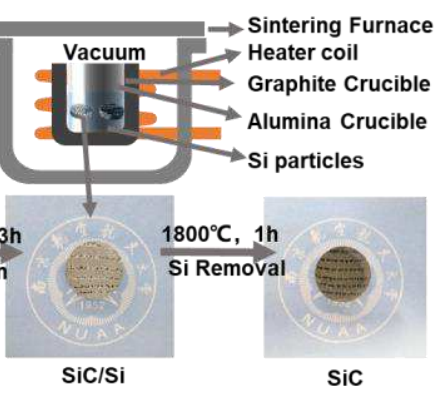

$f$

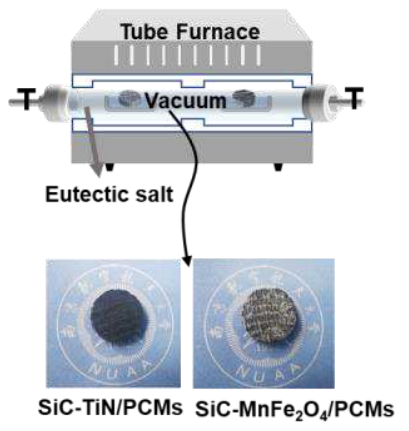

Figure 2. Fabrication processes of nanoparticles decorated biomorphic SiC-PCMs composites.

Six types of wood are selected as the precursor, the scanning electron microscope of carbon templates obtained after pyrolysis are shown in Fig. 3a-f, the view is perpendicular to the direction of growth (axial). As can be clearly seen, carbonized templates basically reproduce the microstructure of the original wood with channels parallel to the tree growth direction of the tree, and no cracks or other obvious damages are observed. Hierarchical pore size distributions are presented for all types of wood, though different woods show a wide variation in the microstructure and porosities.

After molten silicon reactions and removal of the excess Si by sintering at $1800{ }^{\circ} \mathrm{C}$, biomporphic ceramic can be obtained. Their morphologies are given in Fig. 3g-1, which 
have an excellent agreement with those of carbonized templates. No excess silicons are observed in the pores for all samples. The empty pores are used to contain PCMs, so that a high thermal energy storage density can be guaranteed.

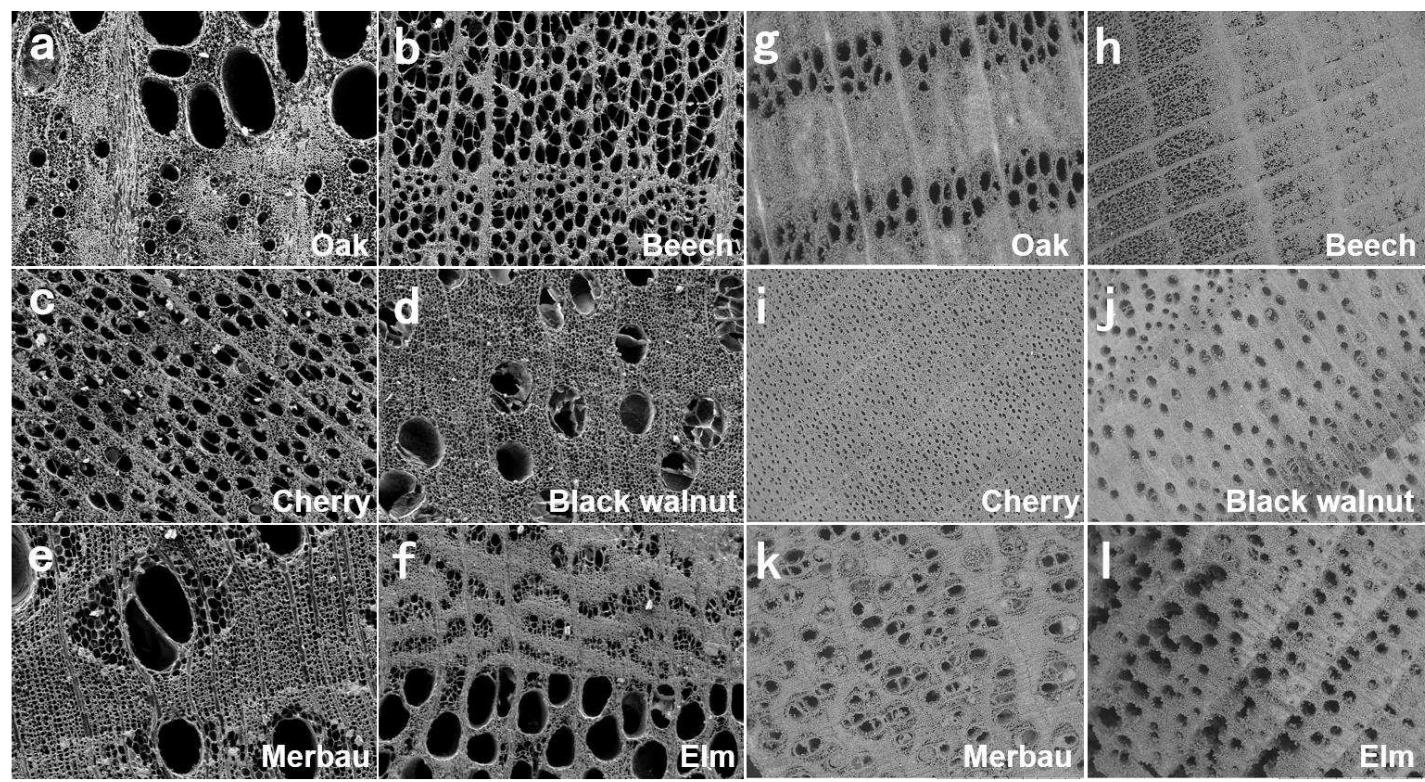

Figure 3. a-f SEM images of carbonized templates (axial sections). g-I SEM images of porous biomorphic $\mathrm{SiC}$ ceramics (axial sections).

To further confirm that all silicon has been removed, X-Ray diffraction patterns of biomorphic $\mathrm{SiC}$ before and after silicon removal are shown in Fig. $4 \mathrm{a}$ and $4 \mathrm{~b}$. Before Si removal, no diffraction peaks of amorphous carbon are observed, indicating that the transformation from carbon template to $\mathrm{SiC}$ is completed. Five strong diffraction peaks at $2 \theta=36.4^{\circ}, 42.18^{\circ}$, and $60.63^{\circ}, 72.39^{\circ}$, and $76.17^{\circ}$ corresponding to cubic type ${ }^{58}(\beta-$ $\mathrm{SiC}$ ) occur, confirming the high purity and high crystallinity of SiC. Besides, three diffraction peaks corresponding to Si are found, so the material is Si crystalline. After Si removal, corresponding XRD patterns of silicon disappear, indicating that there is no silicon left. To further confirm it, scanning electron element mapping images (EDS) of the synthesized biomorphic SiC ceramic are given in Fig. 4c-e. Clear boundaries between $\mathrm{SiC}$ skeletons and pores are presented, and no silicon elements locating inside pores are observed, further demonstrating that no silicon is left. As also revealed by EDS images, SiC grains have large sizes of $30 \sim 50 \mu \mathrm{m}$, which helps to reduce gain 
116 boundary scattering and improve thermal conductivity. The large crystal size can be 117 partially attributed to the high temperature heat treatment $\left(1800{ }^{\circ} \mathrm{C}\right)$ used in the 118 fabrication process to remove the excess silicon, and the grain size may further increase 119 with increasing temperature. Besides, $\mathrm{SiC}$ particles are closely packed with each other, 120 and there are no impurities around the grain boundary, so that phonon-impurity 121 scattering is limited. Large grain sizes and absence of impurities make achieving a high 122 thermal conductivity possible, as will be discussed later.

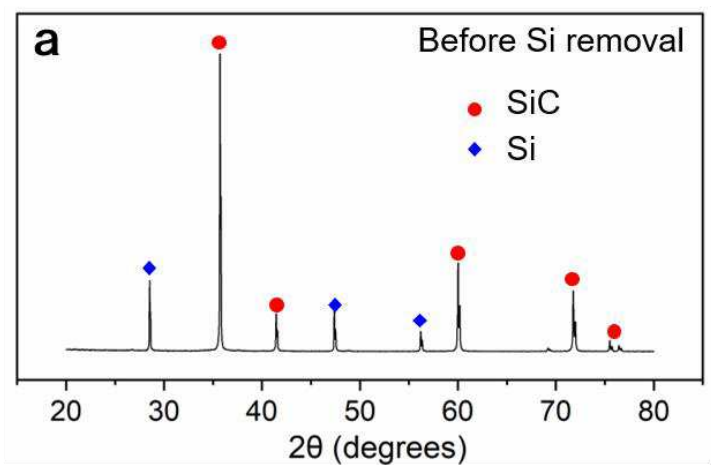

C

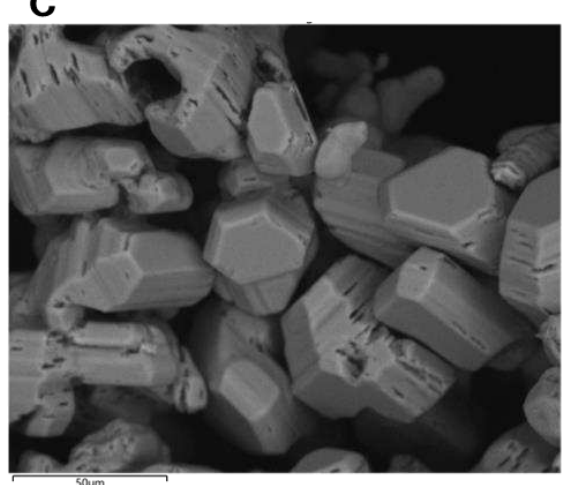

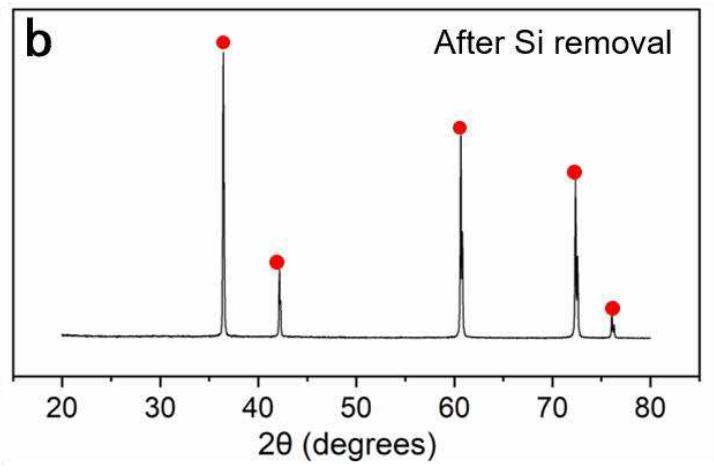

e

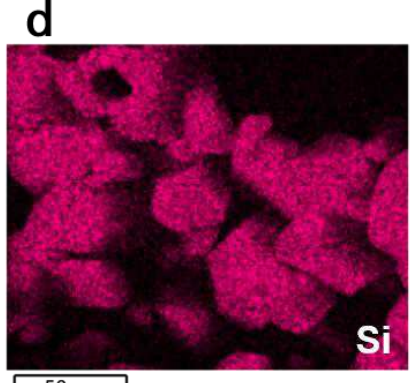

Si

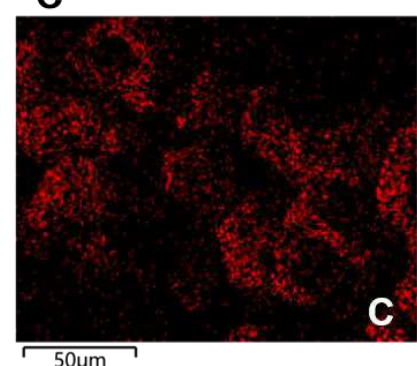

123

124

125

126

127

128

129

131 is considered to be $3.21 \mathrm{~g} / \mathrm{cm}^{3}$. Thermal conductivity $(k)$ was determined according to

132 the measured thermal diffusivity $(\alpha)$, specific heat $\left(C_{p}\right)$, and density $(\rho)^{59}$ : 
134 The specific heat capacity of biomorphic $\mathrm{SiC}$ is measured from room temperature 135 to $400{ }^{\circ} \mathrm{C}$ as given in Fig. 5a, which has a good agreement with literature reports ${ }^{60}$. The 136 specific heat of biomorphic $\mathrm{SiC}$ at room temperature is $0.8 \mathrm{~J} /\left(\mathrm{g}^{\circ} \mathrm{C}\right)$, and gradually 137 increases to $1.28 \mathrm{~J} /\left(\mathrm{g}^{\circ} \mathrm{C}\right)$ at $400{ }^{\circ} \mathrm{C}$. Specific heat capacity values over $400{ }^{\circ} \mathrm{C}$ can be 138 obtained based on extrapolation fitting. Fig. 5b and 5c present thermal conductivity of 139 different biomorphic $\mathrm{SiC}$ samples at room temperature for axial and radial orientations, 140 respectively. The thermal conductivity in the axial direction ranges from $68-113 \mathrm{~W} / \mathrm{mK}$, 141 and the highest thermal conductivity obtained is oak-derived $\mathrm{SiC}$ ceramic $(113 \mathrm{~W} / \mathrm{mK})$ 142 at a porosity of $55.5 \%$. Black walnut-derived $\mathrm{SiC}$ ceramic has the lowest conductivity $143(68 \mathrm{~W} / \mathrm{mK})$ although possessing even a lower porosity of $50 \%$. Therefore, a lower 144 porosity does not necessarily mean a higher thermal conductivity, demonstrating the 145 vital role of microstructures in determining the thermal conductivity. From the 146 comparison between Fig. $5 \mathrm{~b}$ and $5 \mathrm{c}$, it is easy to tell that the thermal conductivity along 147 the radial direction is much lower compared to the radial case. It is very interesting to 148 note that the thermal conductivity of most biomorphic SiC drops all by around $40 \%$ 149 when switching axial to radial directions. The thermal conductivity of black walnut, on 150 the other hand, drops only about $31 \%$, although its thermal conductivity is the lowest 151 for both directions.

152 In real applications, biomorphic $\mathrm{SiC}$ foams operate at the high melting temperature 153 of PCMs, so that it is necessary to check whether the high thermal conductivity can 154 maintain at high temperatures. Without losing generosities, merbau-derived biomorphic $155 \mathrm{SiC}$ is selected, and its thermal conductivity in the axial orientation is given in Fig. $5 \mathrm{~d}$ 156 from room temperature to $1000{ }^{\circ} \mathrm{C}$. The thermal conductivity decreases monotonically 157 with increasing temperature. This is expected since phonon-phonon scattering rates 158 increase prominently at high temperatures, leading to a shorter mean free path of 159 phonons, and thus a lower thermal conductivity. Nevertheless, the thermal conductivity 160 is still considerable with a value as high as $24 \mathrm{~W} / \mathrm{mK}$ when the temperature reaches 
$1611000{ }^{\circ} \mathrm{C}$. Therefore, biomorphic $\mathrm{SiC}$ foams are promising candidates to enhance

162 thermal conductivity of PCMs for a wide temperature range from room temperature to 163 even $1000^{\circ} \mathrm{C}$.
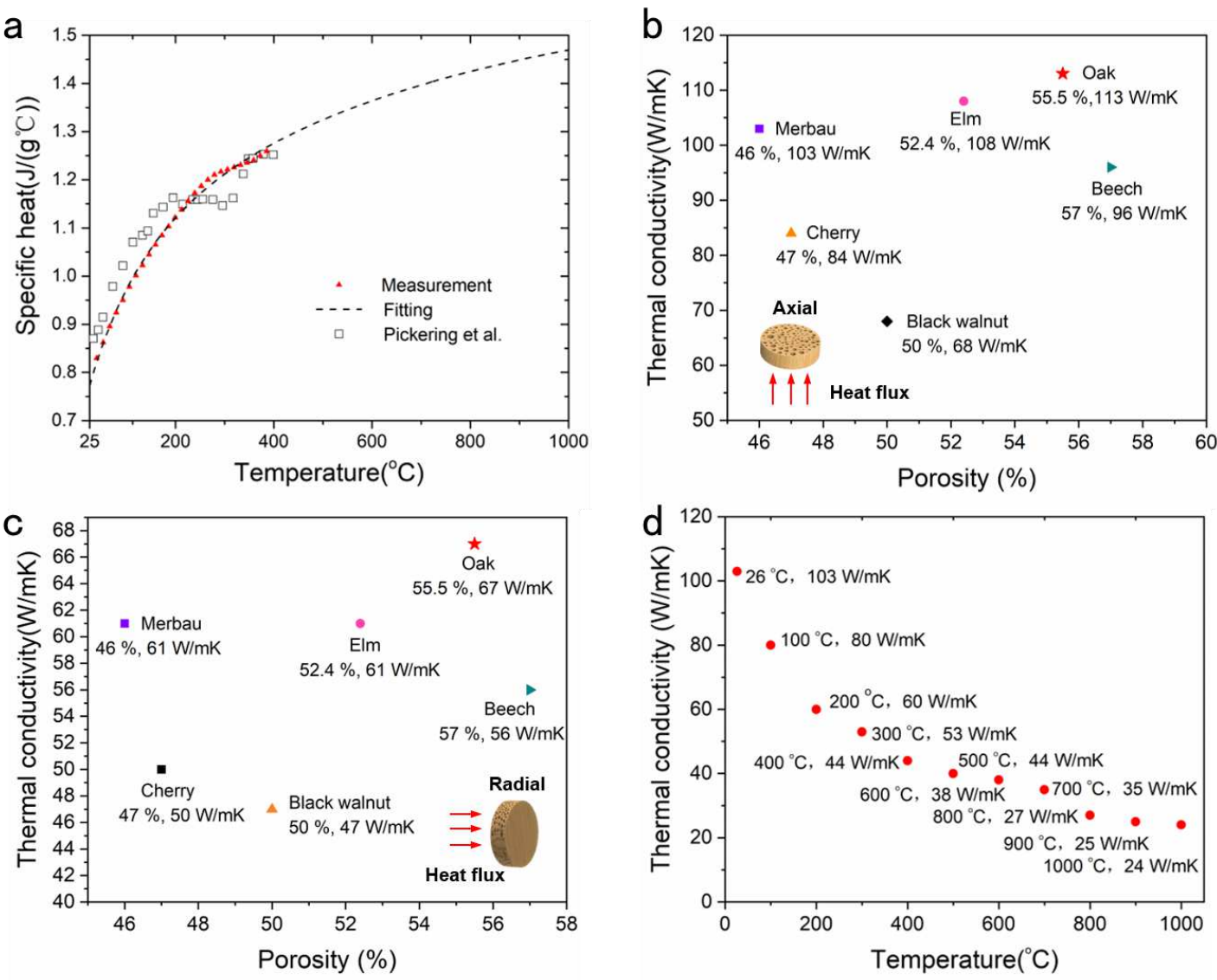

164

Figure 5. a Specific heat of biomorphic $\mathrm{SiC}$ at different temperatures. Thermal conductivity versus

166 porosity at room temperature for both $\mathbf{b}$ axial and $\mathbf{c}$ radial orientation for six kinds of wood derived $\mathrm{SiC}$

167 ceramics. $\mathbf{d}$ Thermal conductivity of Merbau derived $\mathrm{SiC}$ at different temperatures in axial orientations.

Thermal energy storage performances of biomorphic SiC/PCMs composites. The

170 energy storage density of the composite material depends largely on the phase change

171 enthalpy of the PCMs. Here, $\mathrm{NaCl}$ and $\mathrm{KCl}$ are selected as PCMs due to their high

172 phase change enthalpies. The differential scanning calorimetry (DSC) curve of the

173 eutectic PCMs composed of $60 \mathrm{wt} \% \mathrm{NaCl}: 40 \mathrm{wt} \% \mathrm{KCl}$ is the given in Fig. 6a. A high

174 fusion enthalpy of $470.93 \mathrm{~J} / \mathrm{g}$ is obtained, and the starting and ending melting 175 temperature are $600.63{ }^{\circ} \mathrm{C}$ and $716.96{ }^{\circ} \mathrm{C}$, respectively. Such high temperatures are 
176

177

178

179

180

181

182

compatible with next-generation solar power plants, whose operating temperature is expected to be around $700{ }^{\circ} \mathrm{C}$. Oak-derived biomorphic $\mathrm{SiC}$ is employed as the skeleton to package PCMs given its extremely high thermal conductivity. After PCMs are vacuum-impregnated into porous $\mathrm{SiC}$ skeleton, the mass of PCMs is one third of the total sample. The percentage of the retained PCMs is calculated by $\eta=\left(\mathbf{M}_{S i C / P C M}-\mathbf{M}_{S i C}\right) / \mathbf{M}_{S i C / P C M}$, where $\eta$ represents the mass fraction of PCMs, $M_{S i C / P C M}$ denotes the mass of the packaged composites, and $M_{S i C}$ represents the weight of the $\mathrm{SiC}$. The encapsulation mass ratio is $98 \%$, so that the energy storage density of composite material can achieve $157 \mathrm{~J} / \mathrm{g}$, which is consistent with the measured results as given in Fig. 6b. The specific heat of SiC/PCMs composites is given in Fig. 6c. Substituting this value into Eq. (1), the thermal conductivity of composites is obtained as $116 \mathrm{~W} / \mathrm{mK}$. This is the highest thermal conductivity of non-metal based phase change composites, to the best of our knowledge.
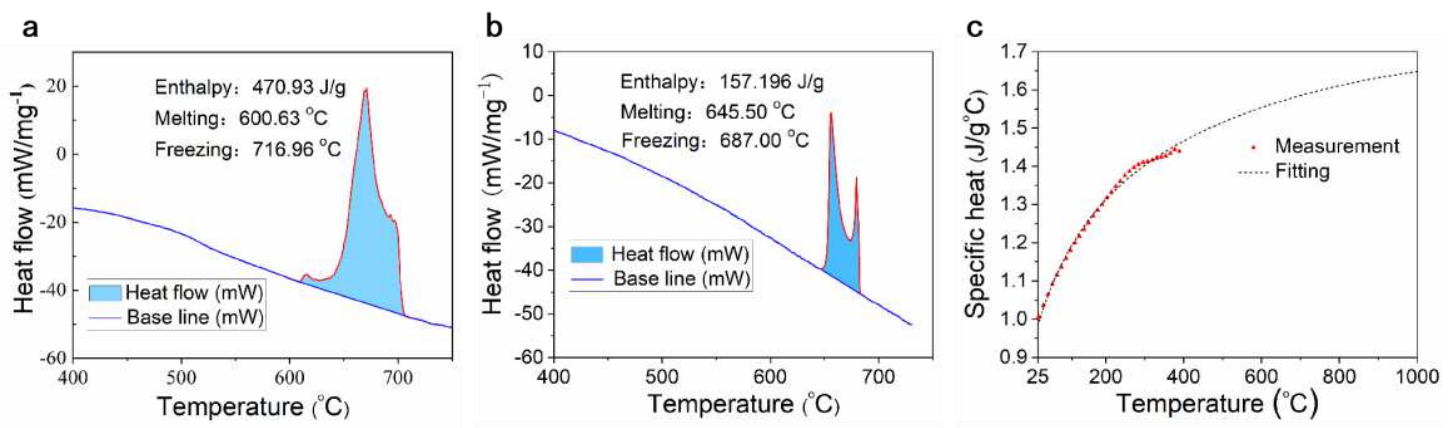

Figure 6. DSC curves of a PCMs, and b SiC/PCMs composites. $\mathbf{c}$ Specific heat of SiC/PCMs composites at different temperatures.

In order to investigate thermal energy storage performances of $\mathrm{SiC} / \mathrm{PCMs}$ composites, surface temperature variations of composites during heating and cooling processes are recorded by an infrared thermal imager (Fig. 7). During the heating process, samples are placed on a graphite plate preheated to $90{ }^{\circ} \mathrm{C}$. For the cooling process, samples are preheated to $90{ }^{\circ} \mathrm{C}$ and then placed on a graphite plate at room temperature immediately. Infrared thermal images of heating and cooling processes are given in Fig. 7a and 7b, respectively. The left and right sample are $\mathrm{SiC} / \mathrm{PCMs}$ 
199 composites and pure PCMs, respectively. Bottom surfaces of both samples are coated 200 with thermal grease to reduce the contact thermal resistance with graphite plate. Top 201 surfaces are also coated with thermal grease to ensure that two samples have the same 202 emissivity, so that thermal images will be the same if both samples are at the sample 203 temperature. As can be seen clearly in Fig. 7a, the temperature of SiC/PCMs composites 204 rises more quickly compared with pure PCMs. Similar phenomena are also observed 205 for cooling processes, as shown in Fig. 7b. To more intuitively demonstrate the surface 206 changes, Fig. 7c and 7d draw the temperature of surface center of both samples for the 207 heating and cooling process, respectively. The maximum temperature increase rate of 208 composites is $17 \mathrm{~K} / \mathrm{s}$, which is 4.2 times as high as that of pure PCMs. Similarly, the 209 maximum temperature drop rate is $26 \mathrm{~K} / \mathrm{s}$ and $6.85 \mathrm{~K} / \mathrm{s}$ for composites and PCMs, 210 respectively. Therefore, we can conclude that incorporating biomorphic $\mathrm{SiC}$ can 211 dramatically increase the thermal conductivity and thus energy storage and release rate 212 of PCMs, making fast charging/discharging possible. 

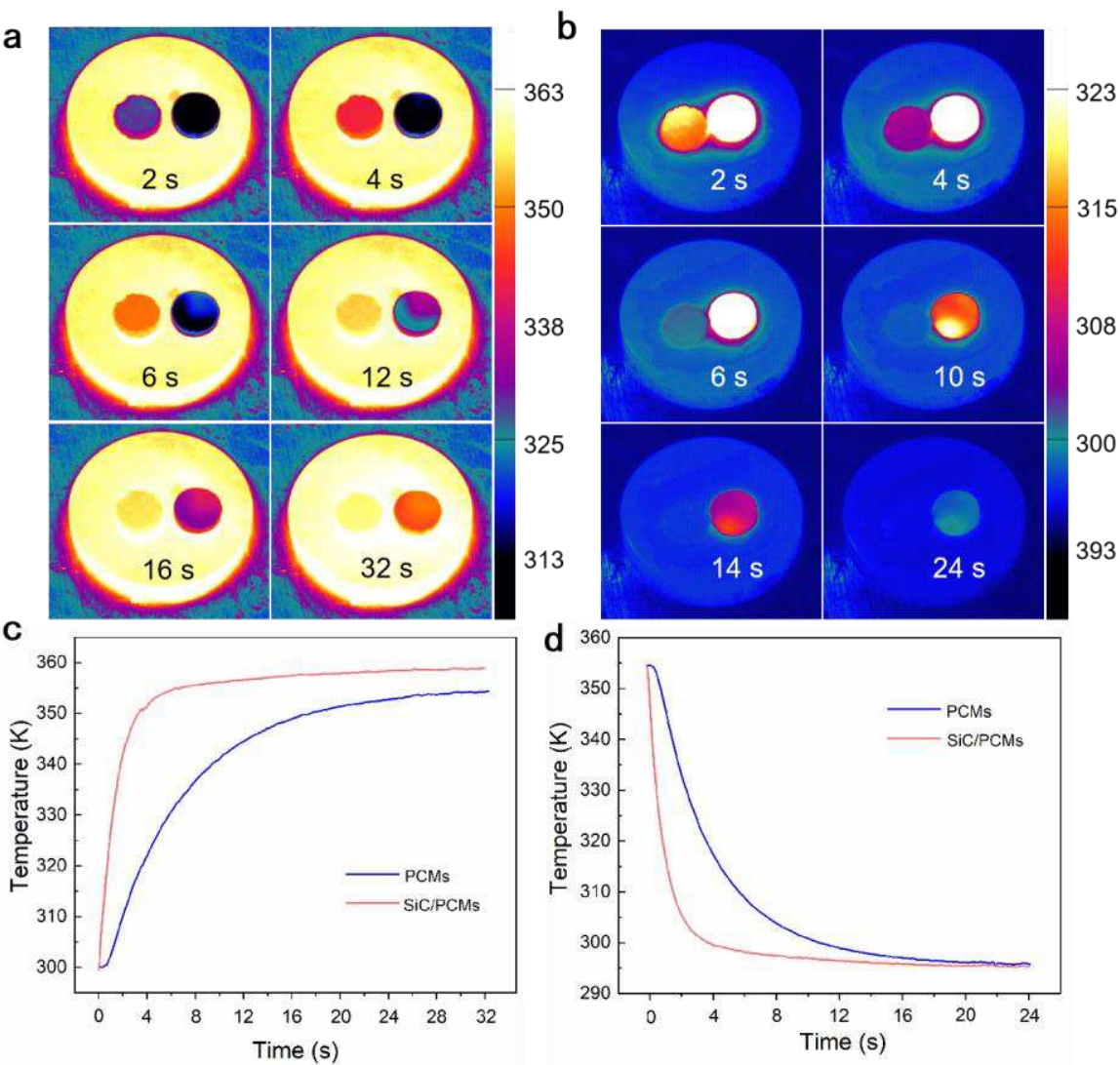

Figure 7. Thermal energy storage properties of SiC/PCMs composites. Infrared thermal images and surface temperature variations for $\mathbf{a}$ heating and $\mathbf{b}$ cooling processes. Temperature profiles at the center of sample surfaces for $\mathbf{c}$ heating and $\mathbf{d}$ cooling processes.

Solar energy storage performances of biomorphic SiC-TiN/PCMs composites.

221 Biomorphic SiC/PCMs have been demonstrated to possess excellent thermal energy 222 storage performances. If we want proposed samples to operate well when the energy 223 source is not heat but solar energy directly, samples should, first of all, possess a high 224 solar absorptance. As shown in Fig. 8a, pure PCMs have a low solar absorptance $A(\lambda)$ 225 especially in the visible range where solar irradiation $S(\lambda)$ is high. Incorporating 226 biomorphic SiC can prominently enhance the solar absorptance for almost all 227 wavelengths from 200 to $2000 \mathrm{~nm}$. As a result, the average solar absorptance, calculated 228 via $A=\int_{200}^{2000} A(\lambda) S(\lambda) \mathrm{d} \lambda / \int_{200}^{2000} S(\lambda) \mathrm{d} \lambda$, is improved from $22.45 \%$ to $82.00 \%$ as can 229 be seen clearly in Fig. 8b. More intuitively, the color changes from white to gray. 
230 Nevertheless, there is still much room for further improving capability of capturing 231 solar energy. Ceramic TiN nanoparticles have been known to trap light well by exciting 232 surface plasmon resonances in a broad band ${ }^{61-63}$. Subsequently, dip coating methods are 233 employed to deposite TiN nanoparticles on biomorphic SiC surfaces in order to further 234 elevate solar absorptance. Black $\mathrm{MnFe}_{2} \mathrm{O}_{4}$ nanoparticles are also investigated. Briefly, $235 \mathrm{TiN}$ or $\mathrm{MnFe}_{2} \mathrm{O}_{4}$ nanoparticles are mixed with deionized water at a ratio of 1:100 (wt \%), 236 the biomorphic $\mathrm{SiC}$ ceramic is dipped in the mixture of TiN-DI or $\mathrm{MnFe}_{2} \mathrm{O}_{4}-\mathrm{DI}$, 237 respectively, and dried at $373 \mathrm{~K}$, followed by sintering processes at $573 \mathrm{~K}$ for 2 hours. 238 The weight increase of samples after being decorated with $\mathrm{TiN}$ or $\mathrm{MnFe}_{2} \mathrm{O}_{4}$ are both 239 approximately $0.01 \mathrm{~g}$, meaning that the percentage of nanoparticles to the whole sample 240 is only about $1.2 \mathrm{wt} \%$. Nevertheless, the spectral absorptance is greatly enhanced for 241 the whole spectrum. As a result, the average solar absorptance achieves $92.17 \%$ and $24295.29 \%$ by decorating $\mathrm{MnFe}_{2} \mathrm{O}_{4}$ and TiN nanoparticles, respectively.

243 EDS images of SiC-TiN/PCMs composites are given in Fig. 8c $8 \mathrm{f}$. As shown in 244 Fig. 8c, the shaded region represents PCMs, whose color is white. Elements of silicon 245 (Si) and potassium (K) represent distributions of biomorphic SiC skeletons and PCMs, 246 respectively, as shown in Fig. 8d and 8e. Skeletons and PCMs are complementary to 247 each other, and most pores are filled with PCMs. This is in a good agreement with the 248 measured loading ratio of PCMs, which is as high as $98 \%$. Distributions of Ti element 249 are very similar to those of $\mathrm{Si}$, as shown in Fig. 8f. This means that TiN nanoparticles 250 indeed are decorated on $\mathrm{SiC}$ surfaces rather than inside pores, which further helping to 251 achieve a high loading ratio of PCMs and thus a high energy storage density. 
a

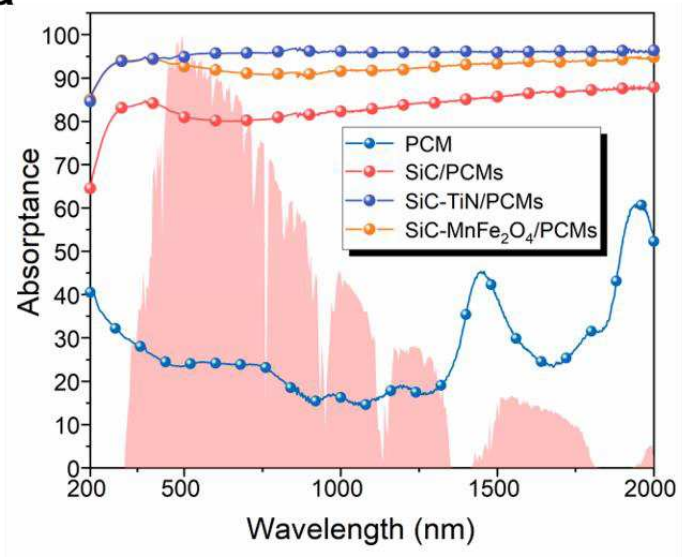

b

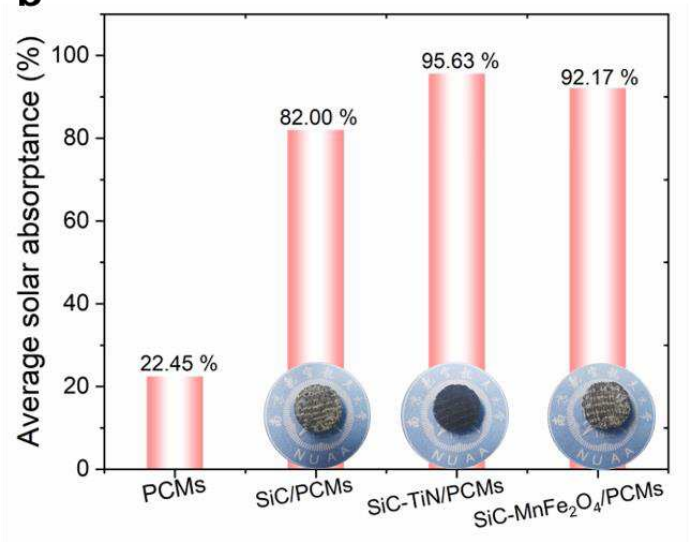

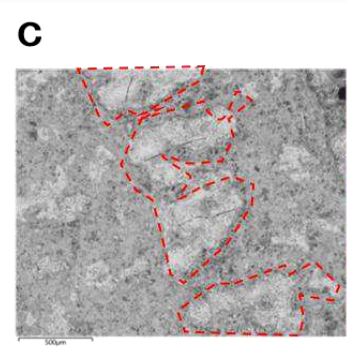

d

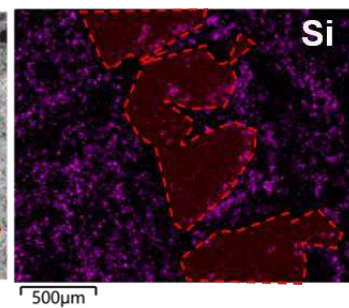

e

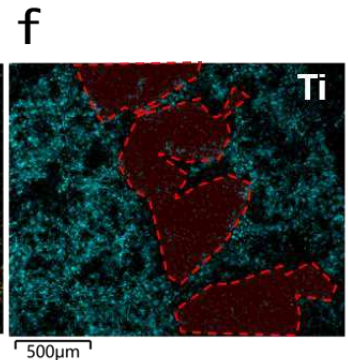

Figure 8. a Spectral and b average solar absorptance of SiC/PCMs, SiC-TiN/PCMs, and SiC-

$\mathrm{MnFe}_{2} \mathrm{O}_{4} / \mathrm{PCMs}$. $\mathbf{c}$ EDS images of the $\mathrm{SiC}-\mathrm{TiN} / \mathrm{PCMs}$, elements of $\mathbf{d}$ silicon ( $\mathrm{Si}$ ), e potassium (K), and f titanium (Ti).

Since both the thermal conductivity and solar absorptance have been enhanced tremendously, now it is time to check the solar energy storage performances of proposed samples. Concentrated solar radiation with a power density of $5 \mathrm{~W} / \mathrm{cm}^{2}$ generated by a solar simulator was used to illuminate the sample from the bottom, as demonstrated in Fig. 9a. Time-sequential IR images of PCMs, SiC/PCMs, and SiC-TiN/PCMs are displayed in Fig. 9b, 9c, and 9d, respectively. For pure PCMs, the temperature increases very slowly under irradiation of light. Main reasons can be attributed to the low thermal conductivity and poor solar absorptance. For SiC/PCMs and SiC-TiN/PCMs, temperature quickly rise to high values even at the beginning 50s due to their high thermal conductivities. The temperature of $\mathrm{SiC}-\mathrm{TiN} / \mathrm{PCMs}$ is higher due to better solar absorption properties enabled by TiN nanoparticles. Fig. 9c draws temperature values of three kinds of thermal storage materials during solar-driven heating and natural cooling processes. Indeed, SiC-TiN/PCMs have the highest energy storage rate under 
the light illumination due to the synthetic effects of high thermal conductivity and high

270 solar absorptance. Fig. 9f gives the temperature change of SiC-TiN/PCMs composites

271 during 12 consecutive heating and cooling cycles. As can be seen clearly, the

272 temperature profile exhibits excellent cycle stability without no obvious deteriorations

273 of the maximum temperature. Therefore, SiC-TiN/PCMs composites are able to achieve

274 fast and stable solar energy storage performances.

a
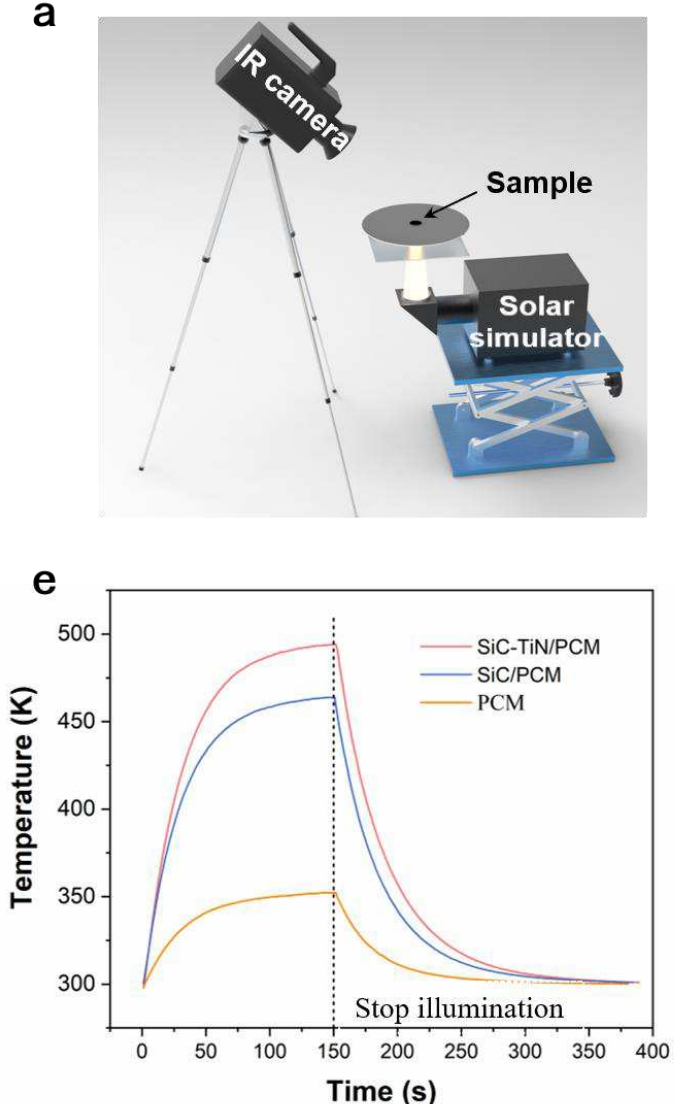

b

C

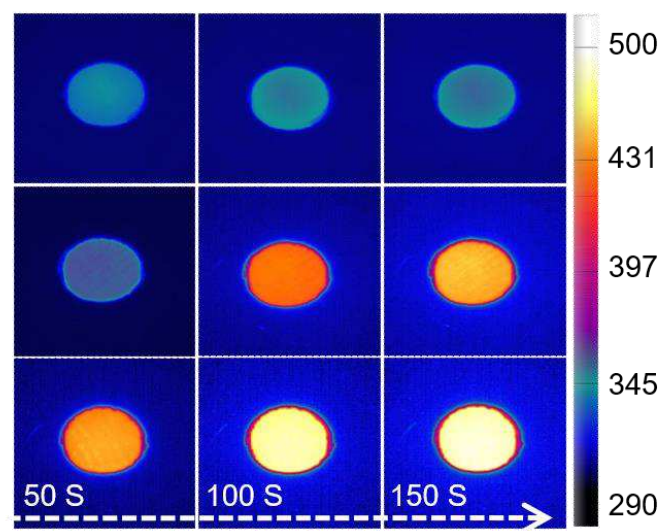

$f$

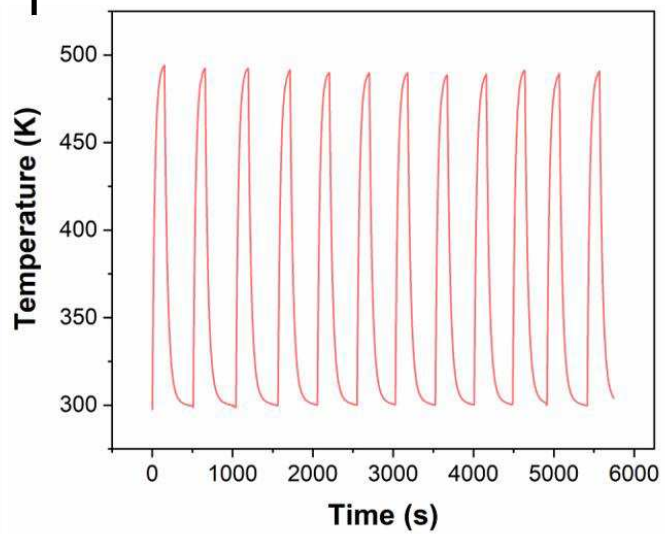

Figure 9. Solar energy storage performances. a Schematic experimental setup. IR images of b pure PCMs, c SiC/PCMs, and d SiC-TiN/PCMs. e Temperature profiles in the center of sample surfaces. f Temperature profiles during repeated heating and cooling processes.

Figure. 10 shows a comparison of the thermal conductivity and the energy density of PCMs composites from the latest reports with our proposals. Some materials possessing high energy storage density, like PC8-90 composite, usually have a low thermal conductivity. One the other hand, after enhancing the thermal conductivity by adding more fillers, the energy storage density will decrease tremendously. High 
284 thermal conductivity and high energy storage density are usually not compatible, but 285 are achieved simultaneously by biomorphic SiC-TiN/PCMs composites. It can be seen 286 clearly, the thermal conductivity of biomorphic SiC-TiN/PCMs composites (116 W/mK) 287 is much larger than currently reported values. The energy storage density of $157 \mathrm{~J} / \mathrm{g}$ is 288 also considerable. Besides storing heat, proposed composites can be also used to store 289 solar energy directly with both excellent solar absorption properties and fast solar 290 energy storage rates.

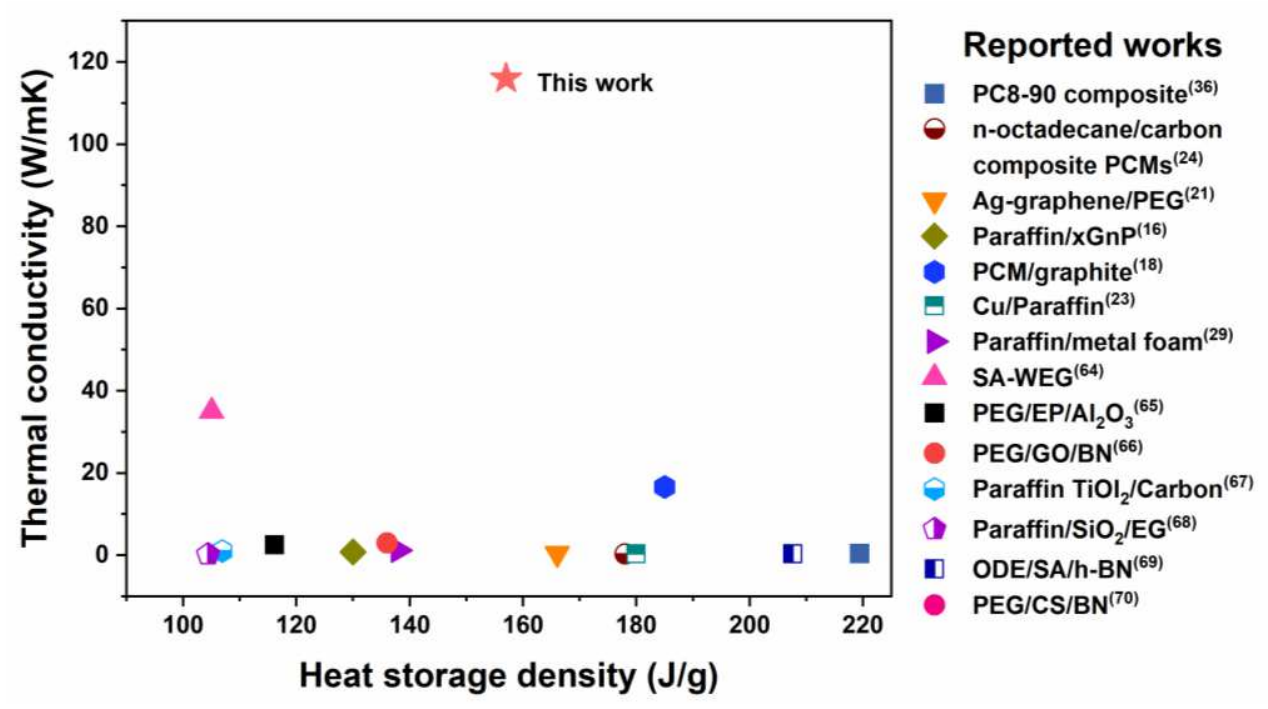

Figure. 10. A comparison of the thermal conductivity and heat storage density of phase change composites from the latest reports

\section{Methods}

296 Preparation processes of biologic ceramics. Porous biomorphic SiC skeletons are 297 fabricated by infiltration of liquid silicon into porous carbon templates obtained from 298 pyrolysis of natural wood. Six wood precursors with different porosities are used: oak, 299 merbau, beech, elm, black walnut, and maple. The manufacturing process consists of 300 three steps. First, the wood specimens are cut, dried for 2 to 3 days at $70{ }^{\circ} \mathrm{C}$, and 301 pyrolyzed in an inert atmosphere, resulting in porous carbon templates. During 302 pyrolysis, a slow heating rate of $0.5{ }^{\circ} \mathrm{C} / \mathrm{min}$ is used up to complete decomposition of 303 the polyaromatic wood polymers (cellulose, hemicellulose, and lignin) at $500{ }^{\circ} \mathrm{C}$. Then 
304 a higher heating rate of $1^{\circ} \mathrm{C} / \mathrm{min}$ up to $900^{\circ} \mathrm{C}$ is used followed by a hold time of $30 \mathrm{~min}$.

305 By using slow heating rates during pyrolysis, crack-free carbon monoliths could be

306 obtained. The porous carbon templates obtained are machined to small disks with 12.7

$307 \mathrm{~mm}$ in diameter and $3 \mathrm{~mm}$ in thickness with their axes parallel (axial - \|) or

308 perpendicular (radial $-\perp$ ) to the tree growth directions as shown in Fig. 2 b.

309 Second, the carbon templates are infiltrated with Si particles $(20-100 \mu \mathrm{m}$, 310 Aladdin $99.99 \%$ purity; shanghai, China) in vacuum at $1600{ }^{\circ} \mathrm{C}$ for $3 \mathrm{~h}$. The quantities 311 of Si particles are above the stoichiometric ratio to carbon to ensure that carbon 312 templates are completely converted to $\mathrm{SiC}$ ceramics, and the time used is enough to 313 achieve complete reaction and stable microstructures. After this process, the resulting 314 material is $\mathrm{SiC} / \mathrm{Si}$ composites that mimics the microstructure of the original wood 315 precursor, and the channels of the sample completely or partially filled with residual 316 silicon (Fig. 2c).

317 Third, the biomorphic $\mathrm{SiC} / \mathrm{Si}$ composites are heated up to $1800{ }^{\circ} \mathrm{C}$ in vacuum to 318 remove the excess $\mathrm{Si}$, the heating rate is $15^{\circ} \mathrm{C} / \mathrm{min}$. In the process of removing excess $319 \mathrm{Si}$, the way to determine whether the $\mathrm{Si}$ has been removed completely is not the 320 sintering time but the change in the vacuum degree. As the temperature rises, the silicon 321 vapor escapes and the vacuum degree gradually increases. When most of the silicon is 322 removed, the vacuum degree gradually decreases. However, there is still silicon left in 323 the pores, one more hour is need to remove the silicon completely. In this process, each 324 sample needs to be placed at intervals, stacking is harmful to sample sintering. Besides, 325 note that the wood contains trace elements, and the decomposition of SiC occurs when 326 it is held for a long time at high temperature. The final material obtained after this 327 process is biomorphic $\mathrm{SiC}$ that consists of a highly porous $\mathrm{SiC}$ skeleton that reproduces 328 the cellular morphology of natural wood (Fig. 2d).

329 In order to enhance the spectral absorbance of $\mathrm{SiC}$ ceramics, titanium nitride and 330 manganese ferrite $\left(\mathrm{MnFe}_{2} \mathrm{O}_{4}\right)$ are employed to be loaded on the $\mathrm{SiC}$ skeleton. Titanium 331 nitride (Aladdin $99.9 \%$; shanghai, China) with particles size of $20 \mathrm{~nm}$ or $\mathrm{MnFe}_{2} \mathrm{O}_{4}$ 
332 (prepared by using sol-gel method) are mixed with deionized water at a ratio of 1:100

$333(\mathrm{wt} \%)$. The wood-derived $\mathrm{SiC}$ ceramics are dipped in the mixture of TiN-DI or

$334 \mathrm{MnFe}_{2} \mathrm{O}_{4}-\mathrm{DI}$, respectively, and dried at $373 \mathrm{~K}$. This process is repeated several times

335 until the green SiC ceramic turned black. And then the SiC samples that loaded with

$336 \mathrm{TiN}$ or $\mathrm{MnFe}_{2} \mathrm{O}_{4}$ are sintered at $573 \mathrm{~K}$ in a Muffle furnace (Fig. 2e).

Preparation of phase change material and $\mathrm{SiC} / \mathrm{PCM}$ composites. Sodium chloride and potassium chloride (60:40 wt\%) (Aladdin 99.5\% AR purity; shanghai, China) are mixed thoroughly in a ball mill at a speed of $300 \mathrm{r} / \mathrm{min}$ for $3 \mathrm{~h}$. Then the mixed salt is dried in nitrogen atmosphere at $423 \mathrm{~K}$ for $24 \mathrm{~h}$ and then dried at $623 \mathrm{k}$ for $2 \mathrm{~h}$ to get the PCMs.

Biomorphic SiC that decorated with nanoparticles and the solid chloride mixture are placed in the container, and heated up to $670{ }^{\circ} \mathrm{C}$ in vacuum for $4 \mathrm{~h}$ to ensure that PCMs are totally melted and infiltrated into the cells, and then cooled down until PCMs are solidified, as shown in Fig. 2 (f).

Characterization. A scanning electron microscope (SEM, Hitachi-FE-SEM-S-4800) equipped with secondary electron (SE) and backscattered electron (BSE) detectors is 350 used to observe the microstructure of biomorphic SiC and SiC-TiN/PCMs, so 351 compositional contrast between the phases could be obtained. Phase analysis are 352 performed by X-ray diffraction (XRD), analyses are carried out in samples before and 353 after the process of Si removal.

354 The enthalpy value of composite PCMs and the specific heat capacity $(C p)$ of the 355 SiC porous sample are investigated using a differential scanning calorimeter (DSC, 356 MET-TLER TOLEDO-DSC-1) at $10{ }^{\circ} \mathrm{C} / \mathrm{min}$ with nitrogen gas flow of $50 \mathrm{~mL} / \mathrm{min}$. Due 357 to the microstructural independence of $C p$ and the same experimental process of all the 358 biomorphic $\mathrm{SiC}$ samples, only one type of biomorphic $\mathrm{SiC}$ is tested and the $C p$ of $\mathrm{SiC}$ 359 skeleton derived from different wood precursor is assumed to be equal. 
The thermal diffusivity $(\alpha)$ of the biomorphic $\mathrm{SiC}$ and the composite sample are 361 measured by the laser flash method (Linseis LFA500), which is a widely used technique 362 to determine the diffusivity of materials. A flash of a laser or a flash xenon lamp is 363 uniformly imparted onto one surface of the cylinder sample. The infrared detector 364 continuously monitors the temperature rise on the opposite side. The temperature versus 365 with time on the opposite of the sample is recorded. The thermal diffusivity value is 366 calculated according to the equation: $\alpha=\omega \mathrm{L}^{2} / \pi \mathrm{t}_{1 / 2}$, where $\alpha$ is the thermal diffusivity in $367 \mathrm{~cm}^{2} / \mathrm{s}, L$ is the sample thickness, $\omega$ is a constant determined by Clark and Taylor 368 approximation and $t_{1 / 2}$ is the time that the other side of the sample to reach half of its maximum temperature.

370 Measurements of the thermal diffusivity in both axial and radial orientations are 371 performed on disk-shaped samples with $12.7 \mathrm{~mm}$ in diameter and $3 \mathrm{~mm}$ in thickness.

372 The diffusivity of the samples in the temperature range of $100-1000^{\circ} \mathrm{C}$ at approximately $373100^{\circ} \mathrm{C}$ intervals was measured in an argon atmosphere. A xenon flash was shot at each 374 samples at least three times, and the data is analyzed by using the software, which 375 including Clark and Taylor approximations. The diffusivity of each sample is obtained 376 by averaging the results of the subsequent rounds after the result of the first time is 377 discarded. At each temperature, three samples from the same wood precursor type and 378 orientation were tested, the results are an average of the three samples. Density was 379 assumed to be constant throughout the high-temperature testing.

\section{Discussion}

382 In summary, we successfully achieved ultrafast both solar and thermal energy storage 383 based on biomorphic $\mathrm{SiC}$ skeletons embedded $\mathrm{NaCl}-\mathrm{KCl}$ molten salts. A record-high 384 thermal conductivity of $116 \mathrm{~W} / \mathrm{mK}$ is realized by replicating cellular structure of oak 385 wood, relieving the low thermal conductivity bottleneck of PCMs. After further 386 decorating TiN nanoparticles on SiC skeletons, excellent solar energy capture capability 387 with $95 \%$ of solar absorptance is achieved via exciting broadband plasmonic resonances. 
388 Excellent thermal transport and solar absorption properties enable designed composites

389 to have bifunctional capabilities of harvesting both thermal energy and solar energy

390 very rapidly. We believe this work opens a new avenue for the design of ceramics based

391 phase change composites to harvest solar and thermal energy simultaneously with a fast

392 rate and high efficiency.

393

394 Data availability. The data that support the findings of this study are available from

395 the corresponding author on request upon reasonable request.

396 


\section{References}

398 1. Steven, Chu, Arun, Nature MJ. Opportunities and challenges for a sustainable 399 energy future. Nature 488, 294-303 (2012).

400 2. Lewis NS. Toward Cost-Effective Solar Energy Use. Science 315, 798-801 $401 \quad$ (2007).

402 3. Ruiting, et al. Reversible temperature regulation of electrical and thermal 403 conductivity using liquid-solid phase transitions. Nature Communications 2, 1404 405

4. Tokoro H, et al. External stimulation-controllable heat-storage ceramics. Nature Communications 6, 1-8 (2015).

5. Kenisarin M, Mahkamov K. Solar energy storage using phase change materials.

Renewable and sustainable energy reviews 11, 1913-1965 (2007).

6. Kenisarin MM. High-temperature phase change materials for thermal energy storage. Renewable and Sustainable energy reviews 14, 955-970 (2010).

7. Mondal S. Phase change materials for smart textiles-An overview. Applied thermal engineering 28, 1536-1550 (2008).

8. Pielichowska K, Pielichowski K. Phase change materials for thermal energy storage. Progress in materials science 65, 67-123 (2014).

9. Sharma A, Tyagi VV, Chen C, Buddhi D. Review on thermal energy storage with phase change materials and applications. Renewable and Sustainable energy reviews 13, 318-345 (2009).

10. Vu MC, Thieu NAT, Choi WK, Islam MA, Kim S-R. Ultralight covalently interconnected silicon carbide aerofoam for high performance thermally conductive epoxy composites. Composites Part A: Applied Science and Manufacturing 138, 106028 (2020).

11. Wuttig M, Yamada N. Phase-change materials for rewriteable data storage. Nature materials 6, 824-832 (2007).

12. Zalba B, Marın JM, Cabeza LF, Mehling H. Review on thermal energy storage with phase change: materials, heat transfer analysis and applications. Applied thermal engineering 23, 251-283 (2003).

13. Lencer D, Salinga M, Grabowski B, Hickel T, Neugebauer J, Wuttig M. A map for phase-change materials. Nature materials 7, 972-977 (2008).

14. A AS, B VVT, A CRC, B DB. Review on thermal energy storage with phase change materials and applications. Renewable \& Sustainable Energy Reviews 13, 318-345 (2009).

15. Han GGD, Li H, Grossman JCJNC. Optically-controlled long-term storage and release of thermal energy in phase-change materials. Nature Communications $\mathbf{8}$, 1-10 (2017).

16. Kim S, Drzal LT. High latent heat storage and high thermal conductive phase change materials using exfoliated graphite nanoplatelets. Solar Energy Materials and Solar Cells 93, 136-142 (2009). 
17. Ling Z, Chen J, Xu T, Fang X, Gao X, Zhang Z. Thermal conductivity of an organic phase change material/expanded graphite composite across the phase change temperature range and a novel thermal conductivity model. Energy Conversion and Management 102, 202-208 (2015).

18. Mills A, Farid M, Selman J, Al-Hallaj S. Thermal conductivity enhancement of phase change materials using a graphite matrix. Applied Thermal Engineering 26, 1652-1661 (2006).

19. Ge Z, Ye F, Ding Y. Composite Materials for Thermal Energy Storage: Enhancing Performance through Microstructures. Chemsuschem 7, 1318 (2014).

20. Shi J-N, et al. Improving the thermal conductivity and shape-stabilization of phase change materials using nanographite additives. Carbon 51, 365-372 (2013).

21. Zhang $\mathrm{Y}$, et al. Ag-graphene/PEG composite phase change materials for enhancing solar-thermal energy conversion and storage capacity. Applied Energy 237, 83-90 (2019).

22. Wang Z, et al. Rapid Charging of Thermal Energy Storage Materials through Plasmonic Heating. Scientific Reports 4, 6246 (2014).

23. $\mathrm{Wu} \mathrm{S}$, Zhu D, Zhang $\mathrm{X}$, Huang J. Preparation and Melting/Freezing Characteristics of $\mathrm{Cu} /$ Paraffin Nanofluid as Phase-Change Material (PCM). Energy \& Fuels 24, 1894-1898 (2010).

24. Teng TP, Yu CC. Characteristics of phase-change materials containing oxide nano-additives for thermal storage. Nanoscale Research Letters 7, 611-611 (2012).

25. Chen J, Yang D, Jiang J, Ma A, Song D. Research progress of phase change materials (PCMs) embedded with metal foam (a review). Procedia Materials Science 4, 389-394 (2014).

26. Chen Z, Gao D, Shi J. Experimental and numerical study on melting of phase change materials in metal foams at pore scale. International journal of heat and mass transfer 72, 646-655 (2014).

27. Li W, Qu Z, He Y, Tao Y. Experimental study of a passive thermal management system for high-powered lithium ion batteries using porous metal foam saturated with phase change materials. Journal of power sources 255, 9-15 (2014).

28. Tian Y, Zhao C-Y. A numerical investigation of heat transfer in phase change materials (PCMs) embedded in porous metals. Energy 36, 5539-5546 (2011).

29. Xiao X, Zhang P, Li M. Preparation and thermal characterization of paraffin/metal foam composite phase change material. Applied Energy 112, 1357-1366 (2013).

30. Zhao C, Lu W, Tian Y. Heat transfer enhancement for thermal energy storage using metal foams embedded within phase change materials (PCMs). Solar energy 84, 1402-1412 (2010). 
31. Zhou D, Zhao C. Experimental investigations on heat transfer in phase change materials (PCMs) embedded in porous materials. Applied Thermal Engineering 31, 970-977 (2011).

32. Wang Y, Tang B, Zhang S. Single - Walled Carbon Nanotube/Phase Change Material Composites: Sunlight - Driven, Reversible, Form - Stable Phase Transitions for Solar Thermal Energy Storage. Advanced Functional Materials 23, 4354-4360 (2013).

33. Wang C, Feng L, Li W, Zheng J, Tian W, Li X. Shape-stabilized phase change materials based on polyethylene glycol/porous carbon composite: the influence of the pore structure of the carbon materials. Solar Energy Materials and Solar Cells 105, 21-26 (2012).

34. Yang Z, Deng Y, Li J. Preparation of porous carbonized woods impregnated with lauric acid as shape-stable composite phase change materials. Applied Thermal Engineering 150, 967-976 (2019).

35. Zhao Y, Min X, Huang Z, Liu Yg, Wu X, Fang M. Honeycomb-like structured biological porous carbon encapsulating PEG: A shape-stable phase change material with enhanced thermal conductivity for thermal energy storage. Energy and Buildings 158, 1049-1062 (2018).

36. Atinafu DG, Dong W, Wang C, Wang G. Synthesis of porous carbon from cotton using an $\mathrm{Mg}(\mathrm{OH}) 2$ template for form-stabilized phase change materials with high encapsulation capacity, transition enthalpy and reliability. Journal of Materials Chemistry A 6, 8969-8977 (2018).

37. Ji R, et al. Enhanced thermal performance of form-stable composite phasechange materials supported by novel porous carbon spheres for thermal energy storage. Journal of Energy Storage 27, 101134 (2020).

38. Li Y, Samad YA, Polychronopoulou K, Alhassan SM, Liao K. From biomass to high performance solar-thermal and electric-thermal energy conversion and storage materials. Journal of Materials Chemistry A 2, 7759-7765 (2014).

39. Huang X, Xia W, Zou R. Nanoconfinement of phase change materials within Carbon Aerogels: Phase Transition Behaviours and Photo-to-Thermal Energy Storage. Journal of Materials Chemistry A 2, 19963-19968 (2014).

40. Li Y, Mai YW, Ye L. Sisal fibre and its composites: a review of recent developments. Composites Science \& Technology 60, 2037-2055 (2000).

41. Shaikh S, Lafdi K, Hallinan KJJoAP. Carbon nanoadditives to enhance latent energy storage of phase change materials. Journal of applied physics 103, 094302 (2008).

42. Xu B, Li ZJE. Paraffin/diatomite/multi-wall carbon nanotubes composite phase change material tailor-made for thermal energy storage cement-based composites. Energy 72, 371-380 (2014).

43. Lane GAJSEM, Cells S. Phase change materials for energy storage nucleation to prevent supercooling. Solar Energy Materials and Solar Cells 27, 135-160 (1992). 
44. Kolpak AM, Grossman JCJNL. Azobenzene-Functionalized Carbon Nanotubes As High-Energy Density Solar Thermal Fuels. Nano Letters 11, 3156-3162 (2011).

45. Sanusi O, Warzoha R, Fleischer ASJIJoH, Transfer M. Energy storage and solidification of paraffin phase change material embedded with graphite nanofibers. International journal of heat and mass transfer 54, 4429-4436 (2011).

46. Pincemin S, Olives R, Py X, Christ MJSEM, Cells S. Highly conductive composites made of phase change materials and graphite for thermal storage. solar Energy Materials and Solar Cells 92, 603-613 (2008).

47. Py X, Olives R, Mauran SJIJoH, Transfer M. Paraffin/porous-graphite-matrix composite as a high and constant power thermal storage material. International journal of heat and mass transfer 44, 2727-2737 (2001).

48. Sar A, Karaipekli AJSEM, Cells S. Preparation, thermal properties and thermal reliability of palmitic acid/expanded graphite composite as form-stable PCM for thermal energy storage. solar Energy Materials and Solar Cells 93, 571-576 (2009).

49. Cottrill AL, et al. Ultra-high thermal effusivity materials for resonant ambient thermal energy harvesting. nature Communications 9, 664 (2018).

50. Mo R, Rooney D, Sun K, Yang HYJNC. 3D nitrogen-doped graphene foam with encapsulated germanium/nitrogen-doped graphene yolk-shell nanoarchitecture for high-performance flexible Li-ion battery. nature Communications 8, 13949 (2017).

51. Liang W, et al. Graphene-nickel/n-carboxylic acids composites as form-stable phase change materials for thermal energy storage. Solar Energy Materials and Solar Cells 132, 425-430 (2015).

52. Zhong Y, Zhou M, Huang F, Lin T, Wan D. Effect of graphene aerogel on thermal behavior of phase change materials for thermal management. Solar Energy Materials and Solar Cells 113, 195-200 (2013).

53. Calderon NR, Martinez-Escandell M, Narciso J, Rodriguez-Reinoso FJJotACS. Manufacture of Biomorphic SiC Components with Homogeneous Properties from Sawdust by Reactive Infiltration with Liquid Silicon. Journal of the American Ceramic Society 93, 1003-1009 (2010).

54. Varela-Feria FM, Ramirez-Rico J, Martinez-Fernandez J, Arellano-Lopez ARD, Singh M. Infiltration and Reaction-Formation Mechanism and Microstructural Evolution of Biomorphic SiC Fabricated by Si-Melt Infiltration. Innovative Processing and Synthesis of Ceramics, Glasses and Composites IX: Proceedings of the 107th Annual Meeting of The American Ceramic Society, Baltimore, Maryland, USA 177, 93 (2012).

55. Gómez-Martín A, Orihuela M, Ramírez-Rico J, Chacartegui R, MartínezFernández J. Thermal conductivity of porous biomorphic SiC derived from wood precursors. Ceramics International 42, 16220-16229 (2016). 
56. Jin Z, Wang J, Qian JJRMM, Engineering. Preparation of biomorphic SiCceramics by the reactive infiltration of $\mathrm{Si}$ into carbon template derived from basswood. Rare Metal Materials and Engineering 33, 1065-1068 (2004).

57. Kardashev BK, Nefagin AS, Smirnov BI, Arellano-Lopez ARD, MartinezFernandez J, Sepulveda RJPotSS. Elastic and inelastic properties of $\mathrm{SiC} / \mathrm{Si}$ biomorphic composites and biomorphic $\mathrm{SiC}$ based on oak and eucalyptus. Physics of the Solid State 48, 1711-1715 (2006).

58. El-Kady O, Fathy AJM, Design. Effect of SiC particle size on the physical and mechanical properties of extruded Al matrix nanocomposites. Materials and Design 54, 348-353 (2014).

59. Zimmermann JW, Hilmas GE, Fahrenholtz WG, Dinwiddie RB, Porter WD, Wang HJJotACS. Thermophysical properties of ZrB2 and ZrB2-SiC ceramics. Journal of the American Ceramic Society 91, 1405-1411 (2008).

60. Pickering MA, Taylor RL, Keeley JT, Graves GA. Chemically vapor deposited silicon carbide (SiC) for optical applications. Proceedings of SPIE - The International Society for Optical Engineering 1118, 2-13 (1989).

61. Ishii S, Sugavaneshwar RP, Nagao T. Titanium nitride nanoparticles as plasmonic solar heat transducers. The Journal of Physical Chemistry C 120, 2343-2348 (2016).

62. Liu Z, Liu G, Huang Z, Liu X, Fu G. Ultra-broadband perfect solar absorber by an ultra-thin refractory titanium nitride meta-surface. Solar Energy Materials and Solar Cells 179, 346-352 (2018).

63. Venugopal N, Gerasimov V, Ershov A, Karpov S, Polyutov S. Titanium nitride as light trapping plasmonic material in silicon solar cell. Optical Materials 72, 397-402 (2017).

64. Zhao Y, Yu B, Yu G, Li W. Study on the water-heat coupled phenomena in thawing frozen soil around a buried oil pipeline. Applied thermal engineering 73, 1477-1488 (2014).

65. Wu B, Lao D, Fu R, Su X, Liu H, Jin X. Novel PEG/EP form-stable phase change materials with high thermal conductivity enhanced by $3 \mathrm{D}$ ceramics network. Ceramics International 46, 25285-25292 (2020).

66. Yang J, et al. Hybrid network structure of boron nitride and graphene oxide in shape-stabilized composite phase change materials with enhanced thermal conductivity and light-to-electric energy conversion capability. Solar Energy Materials and Solar Cells 174, 56-64 (2018).

67. Li Y, Li J, Deng Y, Guan W, Wang X, Qian T. Preparation of paraffin/porous $\mathrm{TiO} 2$ foams with enhanced thermal conductivity as $\mathrm{PCM}$, by covering the $\mathrm{TiO} 2$ surface with a carbon layer. Applied energy 171, 37-45 (2016).

68. Li M, Wu Z, Tan J. Properties of form-stable paraffin/silicon dioxide/expanded graphite phase change composites prepared by sol-gel method. Applied energy 92, 456-461 (2012).

69. Su D, Jia Y, Alva G, Tang F, Fang G. Preparation and thermal properties of n- 
octadecane/stearic acid eutectic mixtures with hexagonal boron nitride as phase change materials for thermal energy storage. Energy and Buildings 131, 35-41 (2016).

70. Jia X, et al. High thermal conductive shape-stabilized phase change materials of polyethylene glycol/boron nitride@ chitosan composites for thermal energy storage. Composites Part A: Applied Science and Manufacturing 129, 105710 (2020).

\section{Acknowledgments}

This work is mainly supported by China National Key Research and Development Plan Project (Nos. 2018YFA0702300) and National Natural Science Foundation of China (No. 51820105010 and 52076106).

\section{Author contributions.}

Y.M. conceived the initial idea. X.L. designed the experiments and worked together with Q.X. to complete most experiments. Q.X also wrote the first draft, and X.L. revised it. Y.N and H.L. provided guidance for thermal conductivity and spectral absorption performance testing. M.C helped with the recording and sorting of experimental data. Y.L. and Y.L. tracked the progress of the experiment and revised the manuscript.

\section{Competing interests}

The authors declare no competing financial interests.

\section{Materials \& Correspondence}

Correspondence and requests for materials should be addressed to X.L.(email:

$$
\text { xliu@nuaa.edu.cn) or to Q.X. (email: xuqiao@nuaa.edu.cn) }
$$


Figures
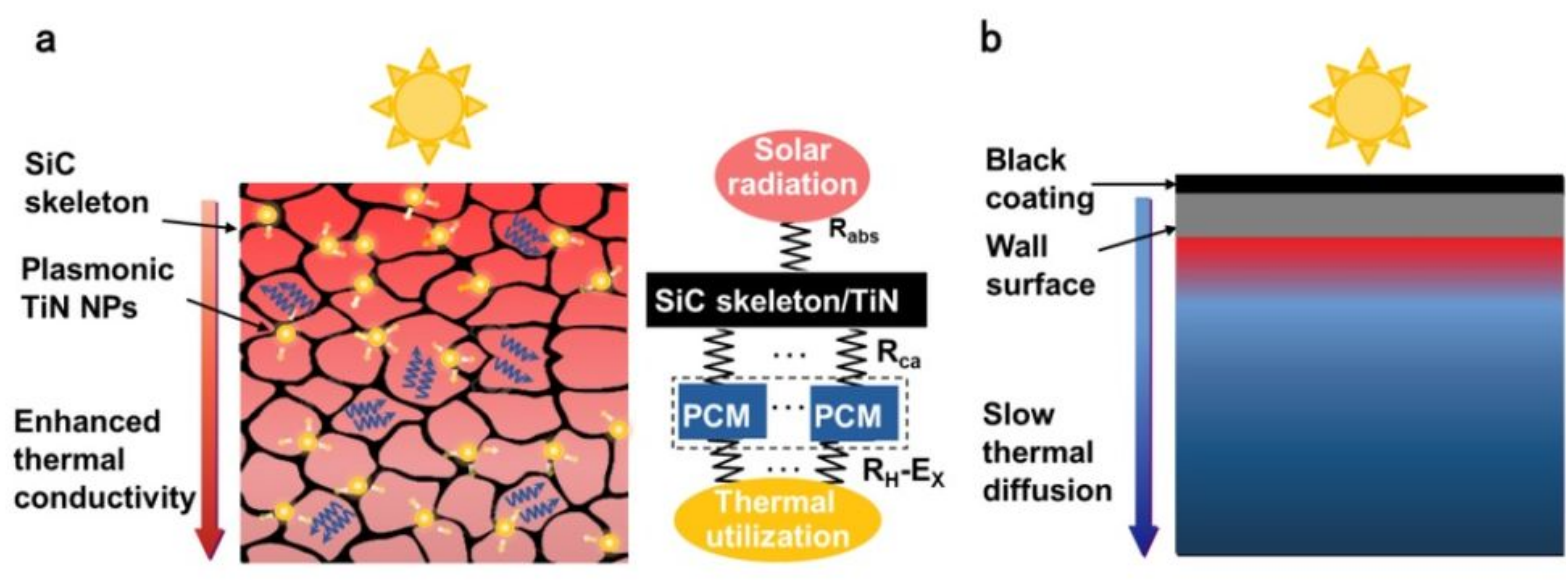

Solar

radiation

$\sum R_{a b s}$

Black coating $\sum_{c d}$

Wall surface

¿ Rcv

PCM

3

PCM

$\sum R_{H}-E_{X}$

hermal

\section{Figure 1}

Schematic illustration of solar energy storage. a Integrated solar thermal conversion and energy storage. b Conventional surface-type. 

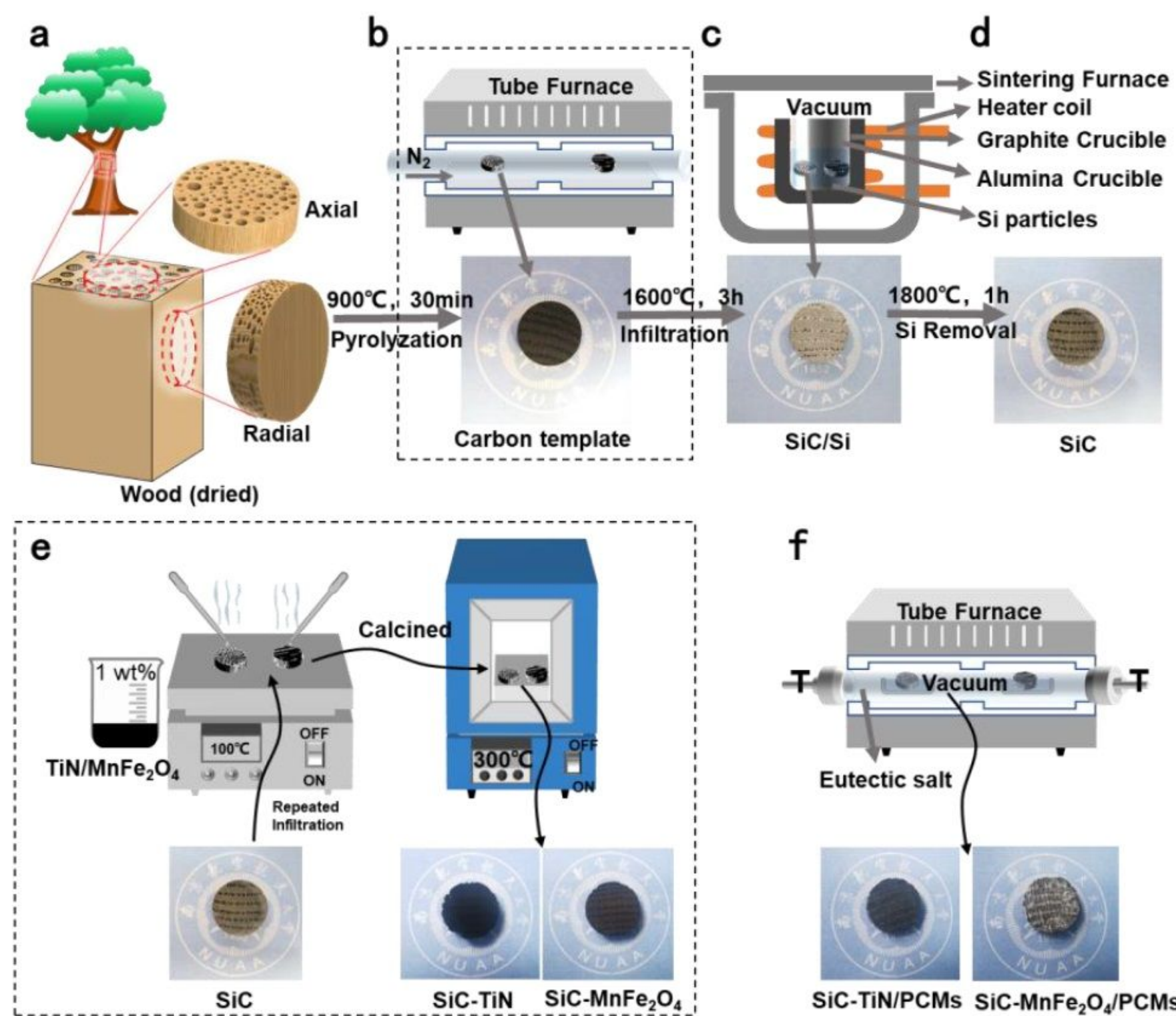

SiC-TiN/PCMs SiC-MnFe $\mathrm{O}_{4} / \mathrm{PCMS}$

Figure 2

Fabrication processes of nanoparticles decorated biomorphic SiC-PCMs composites. 


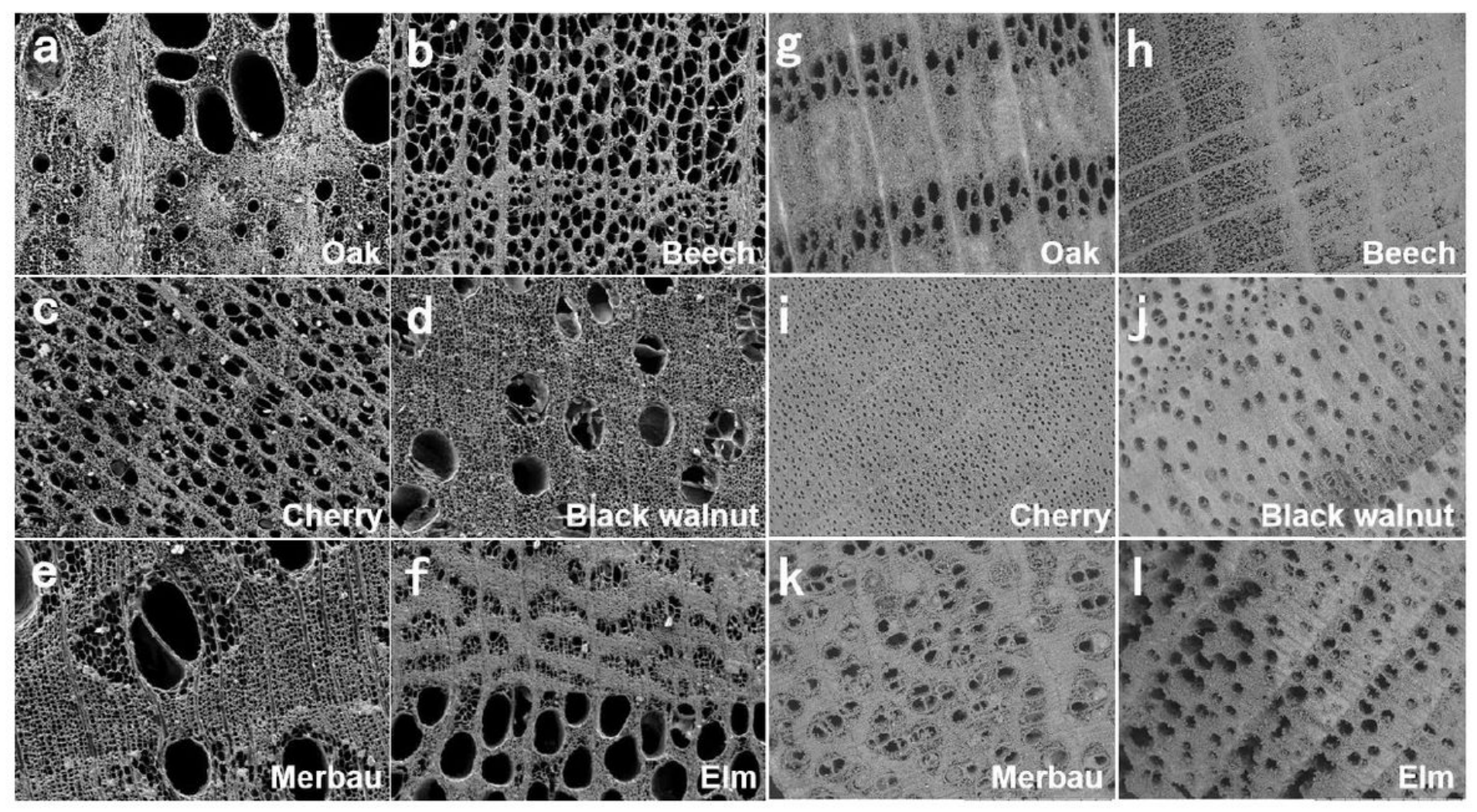

Figure 3

a-f SEM images of carbonized templates (axial sections). g-I SEM images of porous biomorphic SiC ceramics (axial sections). 


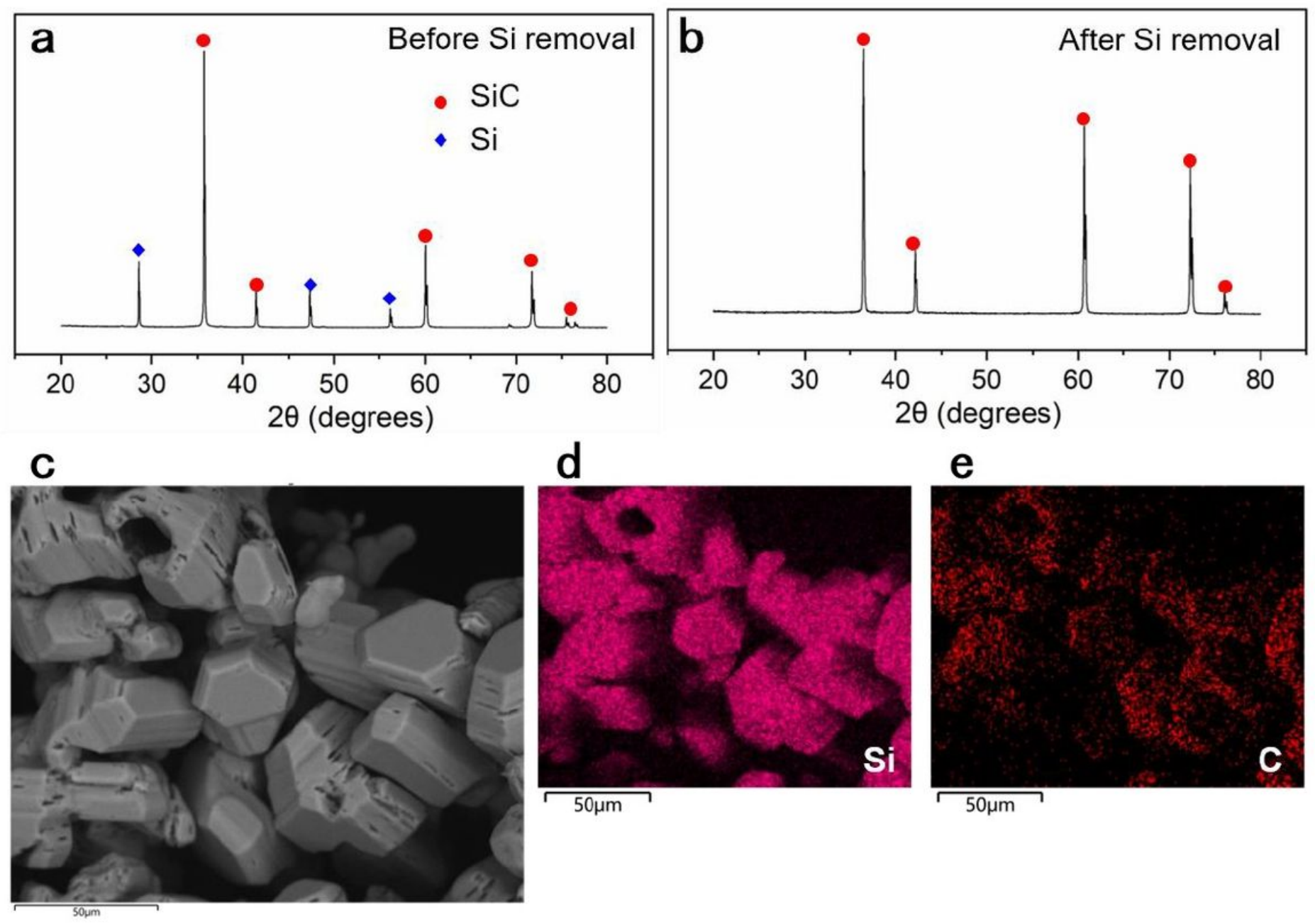

Figure 4

X-ray diffraction patterns of biomorphic SiC ceramics, a before and b after Si removal. c SEM elemental mapping images of biomorphic SiC ceramics, element of d silicon (Si), and e Carbon (C). The ceramic replica was imaged under high vacuum without metal sputtering. 

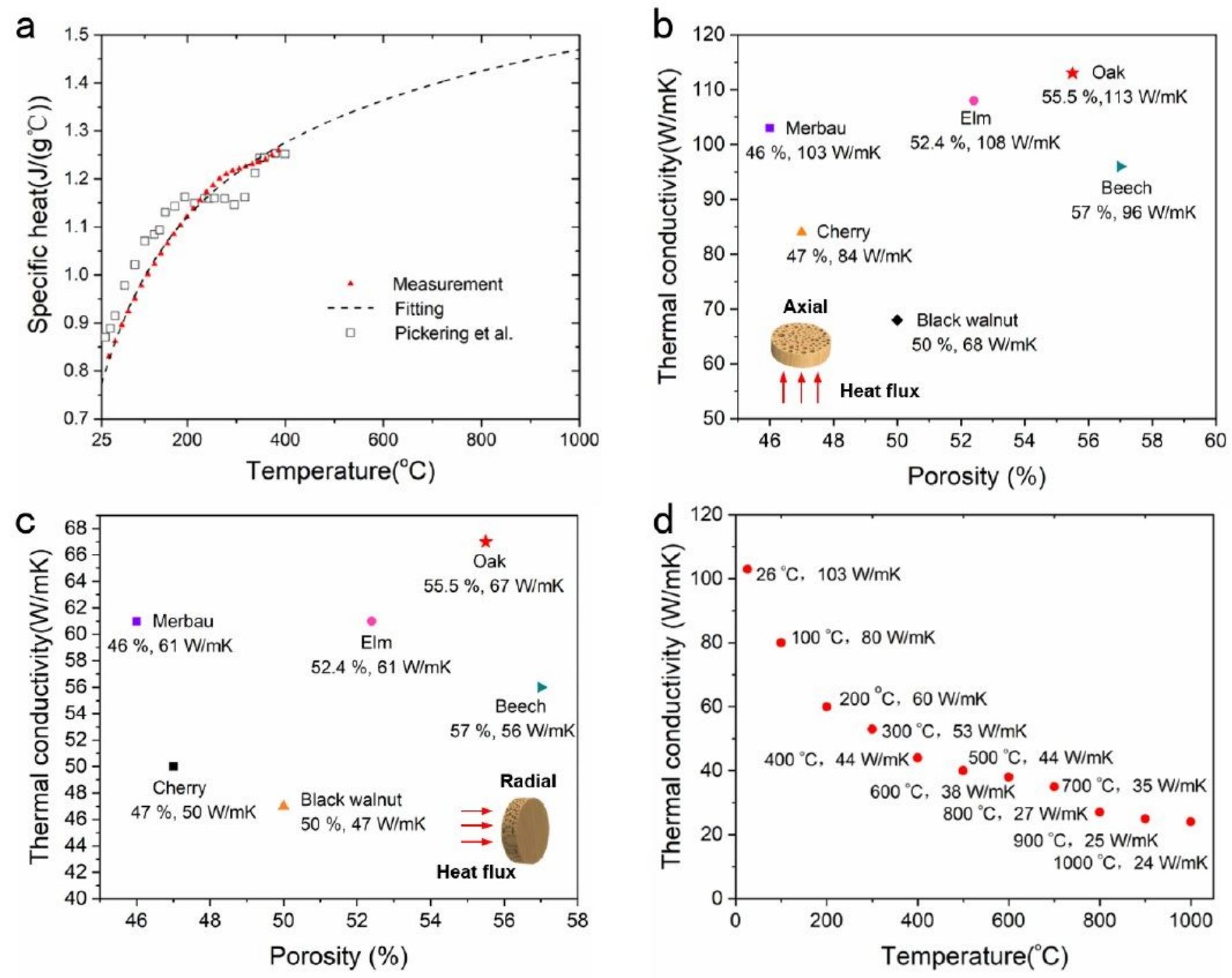

\section{Figure 5}

a Specific heat of biomorphic $\mathrm{SiC}$ at different temperatures. Thermal conductivity versus porosity at room temperature for both $b$ axial and $c$ radial orientation for six kinds of wood derived SiC ceramics. $d$ Thermal conductivity of Merbau derived SiC at different temperatures in axial orientations.
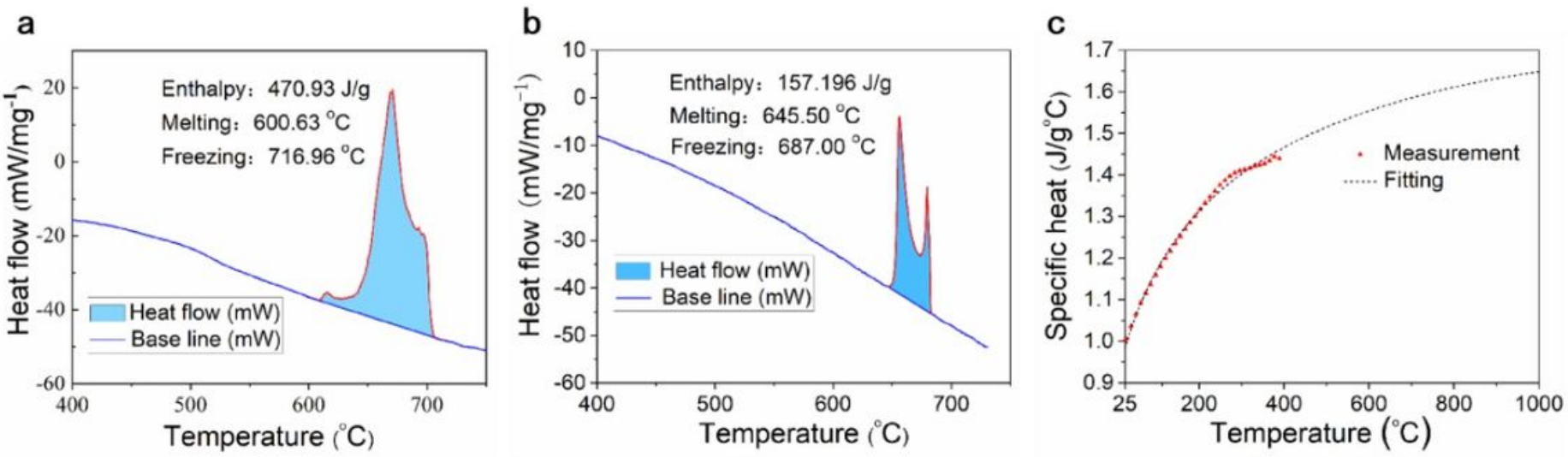
DSC curves of a PCMs, and b SiC/PCMs composites. c Specific heat of SiC/PCMs composites at different temperatures.
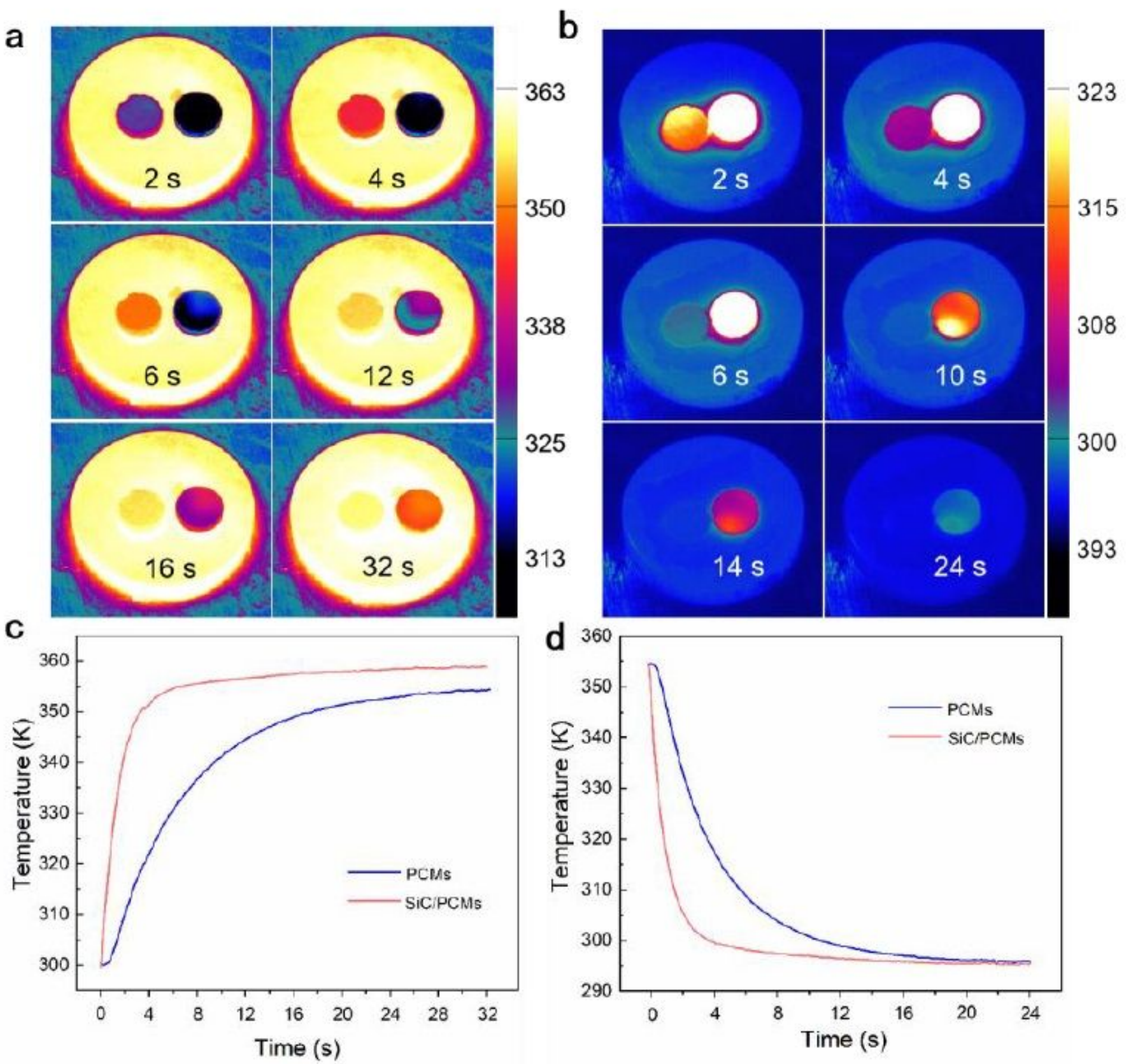

\section{Figure 7}

Thermal energy storage properties of SiC/PCMs composites. Infrared thermal images and surface temperature variations for a heating and $b$ cooling processes. Temperature profiles at the center of sample surfaces for $\mathrm{c}$ heating and $\mathrm{d}$ cooling processes. 
a

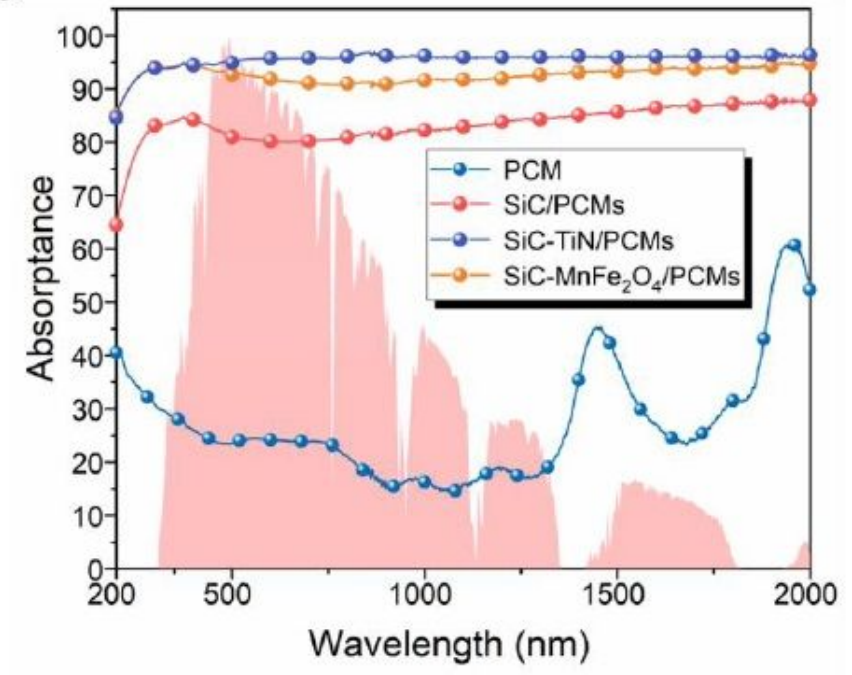

b

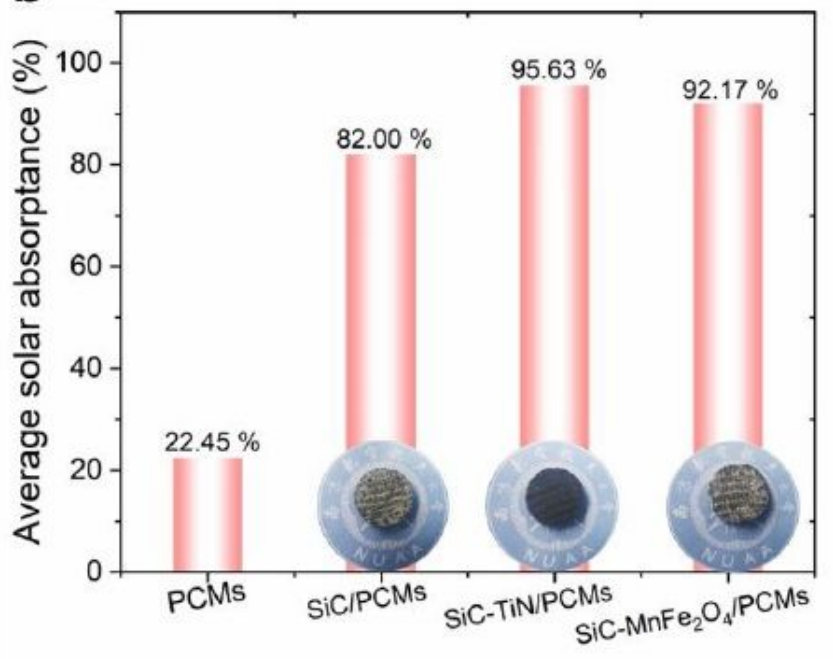

e

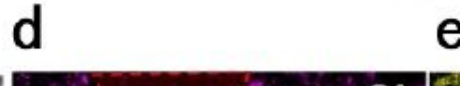

7. Si

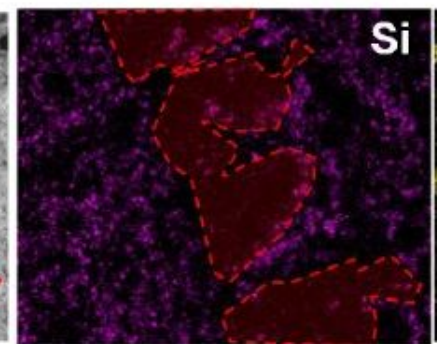

$500 \mu \mathrm{m}$

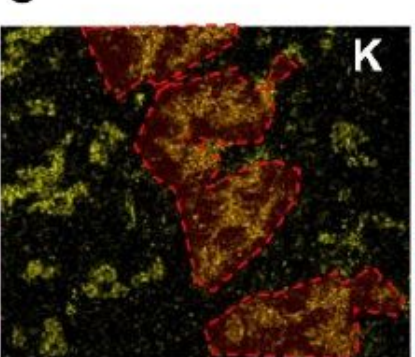

$500 \mu \mathrm{m}$ $f$

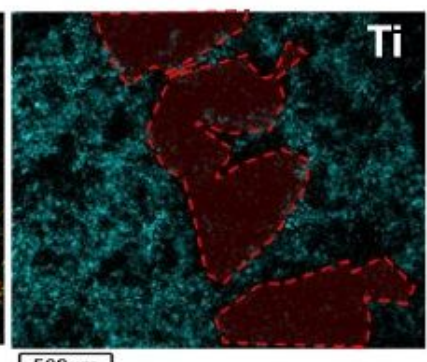

$500 \mu \mathrm{m}$

\section{Figure 8}

a Spectral and b average solar absorptance of SiC/PCMs, SiC-TiN/PCMs, and SiC- MnFe204/PCMs. C EDS images of the SiC-TiN/PCMs, elements of $d$ silicon (Si), e potassium (K), and $f$ titanium (Ti). 
a
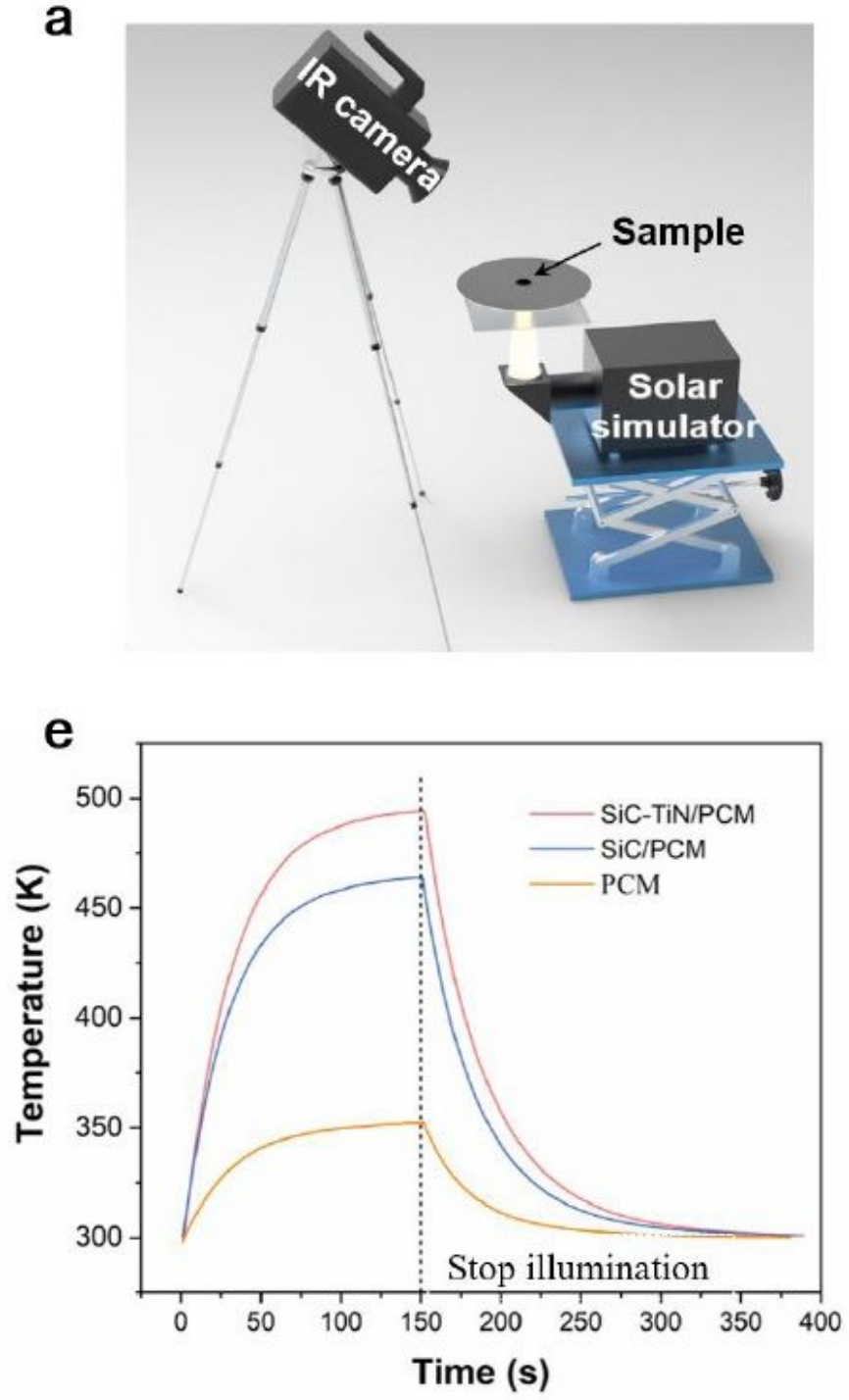
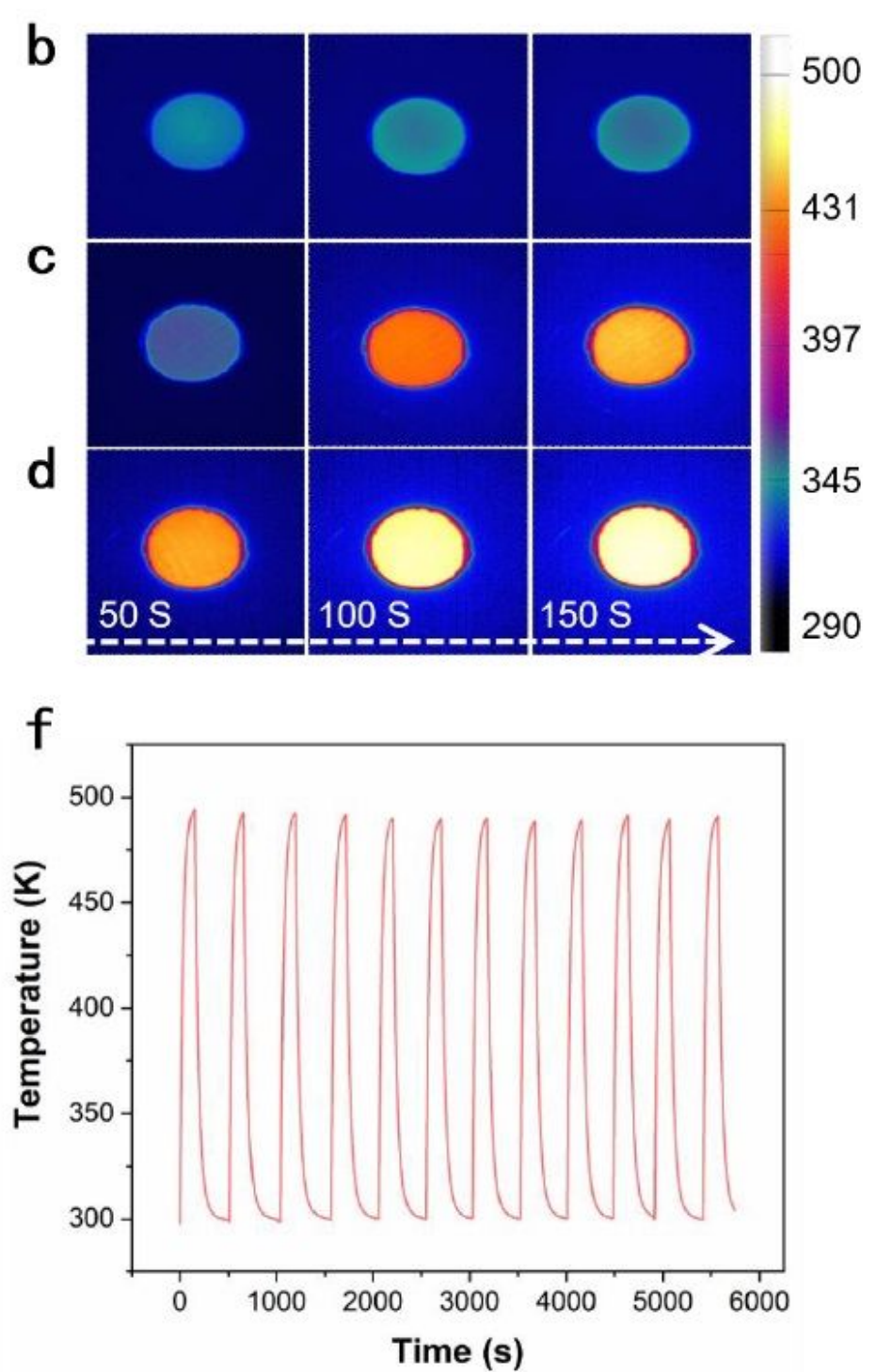

\section{Figure 9}

Solar energy storage performances. a Schematic experimental setup. IR images of b pure PCMs, c $\mathrm{SiC} / \mathrm{PCMs}$, and $\mathrm{d} \mathrm{SiC}-\mathrm{TiN} / \mathrm{PCMs}$. e Temperature profiles in the center of sample surfaces. $f$ Temperature profiles during repeated heating and cooling processes. 


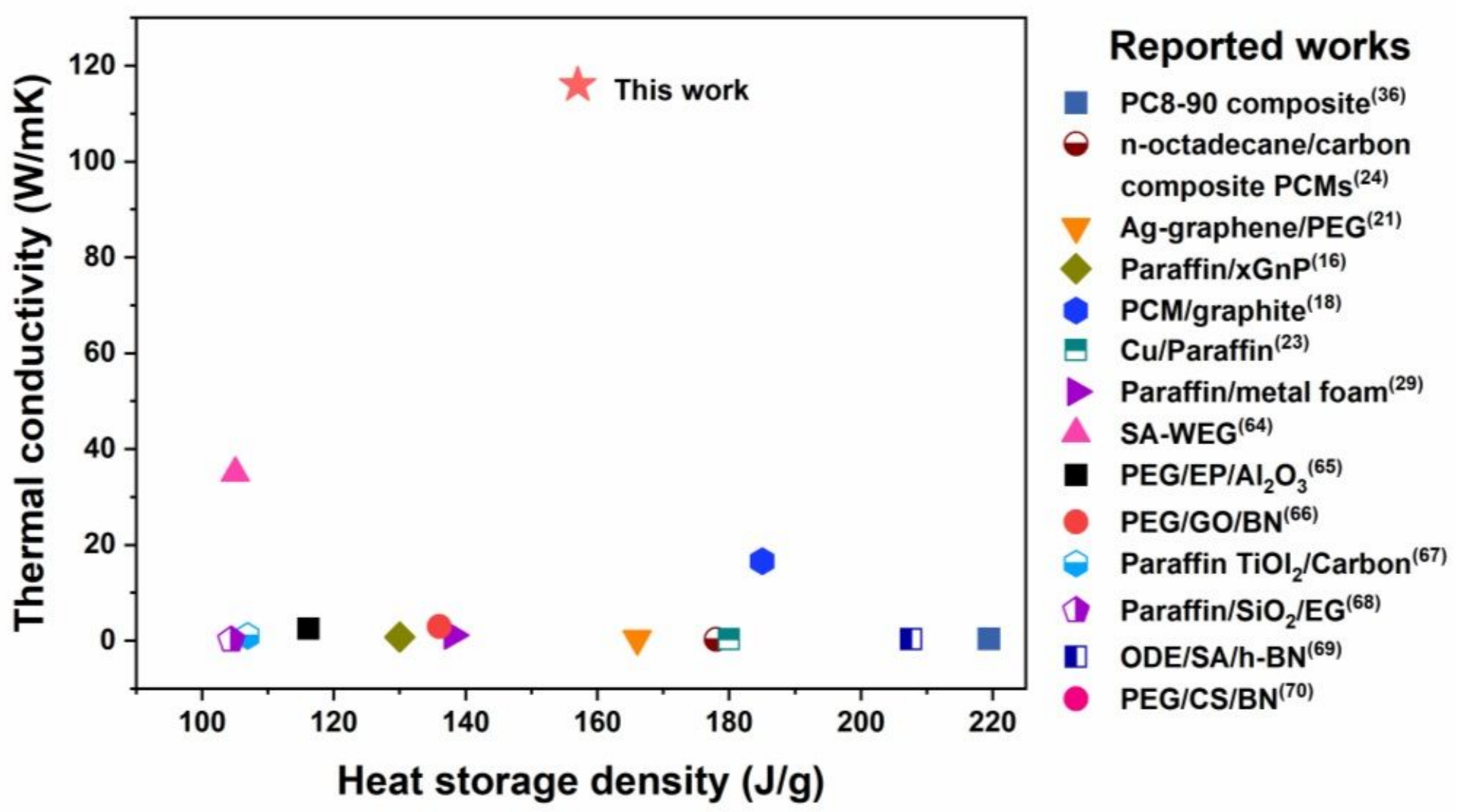

Figure 10

A comparison of the thermal conductivity and heat storage density of phase change composites from the latest reports 